\title{
12. Cross-Jurisdictional Performance Audits: Impacts and options for the Australian National Audit Office
}

\author{
Patricia Gerald
}

'To attack the Auditor-General, is to seek to weaken the Parliament. To weaken the Parliament's ability to hold the executive to account is to attack and weaken the centrepiece of our defences against tyranny and corruption. It is an attack on the people itself.'

- Former Commonwealth Auditor-General, John Taylor (The Age, 5

December 1996, p. 17)

\section{Introduction}

The lack of auditing of Commonwealth transfers to states and territories in Australia has been described as a 'glaring gap' in the accountability of Commonwealth spending (Wanna and Podger 2009). Payments to the states and territories amounted to $\$ 97$ billion in 2011-12, representing 25.7 per cent of total Commonwealth expenditure, a significant source of funding for services provided to Australians including education, health, and Indigenous programs (Australian Government 2012). Some of these transfers are unconditional, but many are conditional, with specific Commonwealth objectives or expected outcomes. In 2011-12, conditional transfers amounted to \$49.9 billion (Australian Government 2012). Although the Commonwealth Parliament remains accountable for the efficient and effective spending of conditional funds by the recipient states and territories, according to the pre-agreed terms, the Commonwealth Auditor-General has not reviewed these transfers.

The governing legislation of the Commonwealth Auditor-General is regularly reviewed by the Joint Committee of Public Accounts and Audit (JCPAA), a parliamentary committee tasked with ensuring that audit legislation remains current, relevant and sufficient for the Auditor-General to carry out his mandate. The 2009 review, 'Inquiry into the Auditor-General Act 1997', highlighted gaps in accountability, particularly in areas of spending made by 'agents' of the Commonwealth: a private sector contractor, non-governmental organisation (NGO), government business enterprise (GBE), or other level of government, such as a state, territory or local government. The review resulted in several amendments to the Commonwealth Auditor-General Act 1997, including the 
addition of powers to allow the conduct of performance audits of these agents, referred to as 'Commonwealth Partners'. These powers often referred to as 'follow-the-money' provisions were awarded to the Auditor-General with the intent of addressing these gaps in accountability.

As the Commonwealth Auditor-General begins to conduct these audits, in the case of state and territory governments it will involve crossing jurisdictional and constitutional boundaries into areas traditionally accessed only by state and territory auditors-general. Such access could impact a variety of stakeholders and further strain an already tenuous Commonwealth-state relationship. The Commonwealth Auditor-General is wading into politically and administratively sensitive terrain.

This study examines the new provision allowing the Commonwealth AuditorGeneral to conduct audits of states and territories, referred to in this report as cross-jurisdictional performance audits (CJPAs), and seeks to answer two central research questions:

- How will the introduction of CJPAs of states and territories by the Commonwealth Auditor-General likely impact key stakeholders, including the Australian National Audit Office (ANAO)?

- How does this approach to inter-jurisdictional auditing compare to alternative approaches such as cooperative audits, both in Australia and internationally? By identifying areas of impact, this investigation seeks to help the ANAO anticipate challenges to the introduction of CJPAs, promote discussion about alternatives, and develop options for optimal implementation.

This research is informed by a review of the literature on performance audit, an international scan of the mandates of other auditors-general, interviews with Australian auditors-general and other key individuals, and an online survey of national audit offices in other jurisdictions on their views on interjurisdictional auditing. Based on these findings, a summary of key stakeholder impacts is presented, including impacts on the ANAO's performance audit process, followed by a framework for comparing different approaches to interjurisdictional audit and options for implementation at the ANAO.

\section{Background and context}

This section provides necessary background about the Commonwealth AuditorGeneral and the events leading up to the current amendments. ${ }^{1}$ First, it provides an overview of the role of the Auditor-General and performance audit at the

\footnotetext{
1 Information in this section was gathered from a variety of sources including gray literature, government and professional association websites, internet searches, news media, academic journals and books.
} 
ANAO. It then outlines the current state of Commonwealth-state relations, with a specific focus on federal financial transfers and why they are a concern in terms of auditing and accountability. This is followed by a review of the amendment process and outcomes. The final part identifies the Auditor-General's key stakeholder relationships.

\section{Accountability and the role of the Auditor-General}

The Commonwealth Auditor-General is an independent officer of the legislature responsible to the federal Parliament for providing oversight of government operations and expenditures (see Figure 1). The Auditor-General supports accountability through the provision of financial, compliance and performance auditing services to Parliament and all federal public sector entities (ANAO 2011). Supported by the ANAO and broad access-to-information and premises powers under the AuditorGeneral Act 1997, the Auditor-General can identify areas for investigation and recommend improvements in public administration and service delivery (ANAO 2011). Despite the combined revenues and expenses of the General Government Sector of some $\$ 675$ billion, the ANAO carries out its oversight duties with an annual budget of only $\$ 78 \mathrm{~m}$, or roughly 0.01 per cent of the total (McPhee 2011).

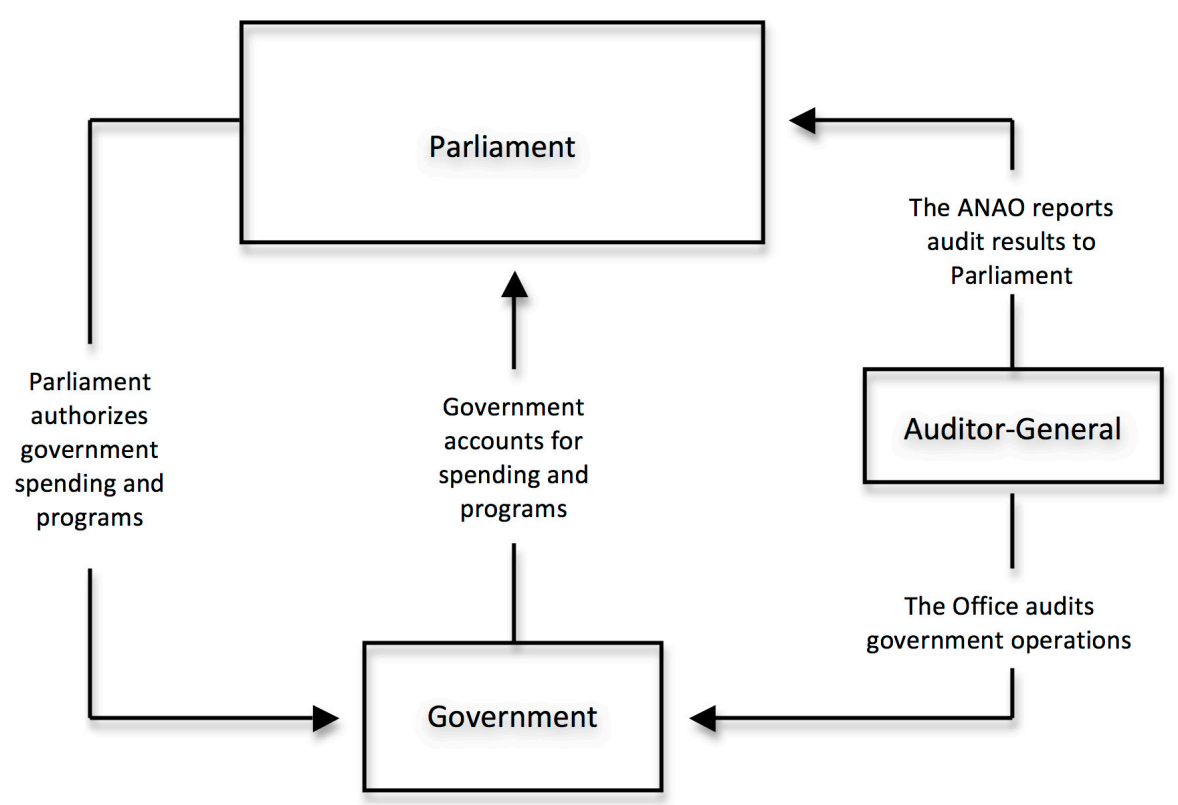

Figure 1: The role of the Auditor-General as an independent officer of the Parliament

Source: Adapted from Office of the Auditor-General of Canada 2007, p.4. 


\section{Performance audit}

Until 1979, the Auditor-General provided oversight through traditional audit practices known as financial or attest audits, and, in some cases, through compliance audits. Over the years it became increasingly clear that a financial account of how much was spent did not tell an adequate story for accountability purposes as to how well money had been spent, or whether value for money had been achieved. Something was needed to assess the managers and departments responsible for making spending and operational decisions, especially in light of 'perceived concerns about wasteful use of money and other resources' (Wanna, Ryan and Ng 2001, pp. 206-207).

In 1979, the ANAO was given the authority to carry out 'efficiency audits', which marked the beginning of an entirely new role for the Auditor-General, and a major expansion in his work. It also led a fundamental change in the ANAO's relationship with stakeholders (Wanna, Ryan and Ng 2001, p. 203), particularly with the departments and agencies they audit, known as 'auditees'. No longer simply reviewing financial accounts, auditors would develop auditspecific performance criteria and assess management performance against those criteria. Some areas of the public sector resisted the new practices, which were seen as 'a threat to their operations, responsibilities and policy capabilities' (Wanna, Ryan and Ng 2001, p. 204). By 1997, new legislation renamed efficiency audits as 'performance audits' (see Figure 2), and today they represent about 40 per cent of the ANAO's overall spending (ANAO 2012b). Approximately 56 performance audits are conducted and tabled in Parliament each year. ${ }^{2}$

\section{The Australian federal context}

As in many federal nations, the relationship between the Commonwealth and state governments in Australia is often strained. Since the Commonwealth has few exclusive powers but is involved to a high degree in shared functions, grievances between the jurisdictions often stem out of conflicts over the Commonwealth's involvement in these areas that are constitutionally the responsibility of the states (see Twomey and Withers 2007). This is compounded by a vertical fiscal imbalance, which sees the Commonwealth centrally raising the majority of the tax revenue while the states, with limited revenue-raising capacity, are left with higher public expenditure demands that 'greatly exceed' their revenue-raising capacity (Quiggan 2005, p. 2). For example, Australian states do not have access to income tax revenues unlike many other federations (see Figure 3).

2 The number of performance audits undertaken can vary slightly from year to year. 
12. Cross-Jurisdictional Performance Audits

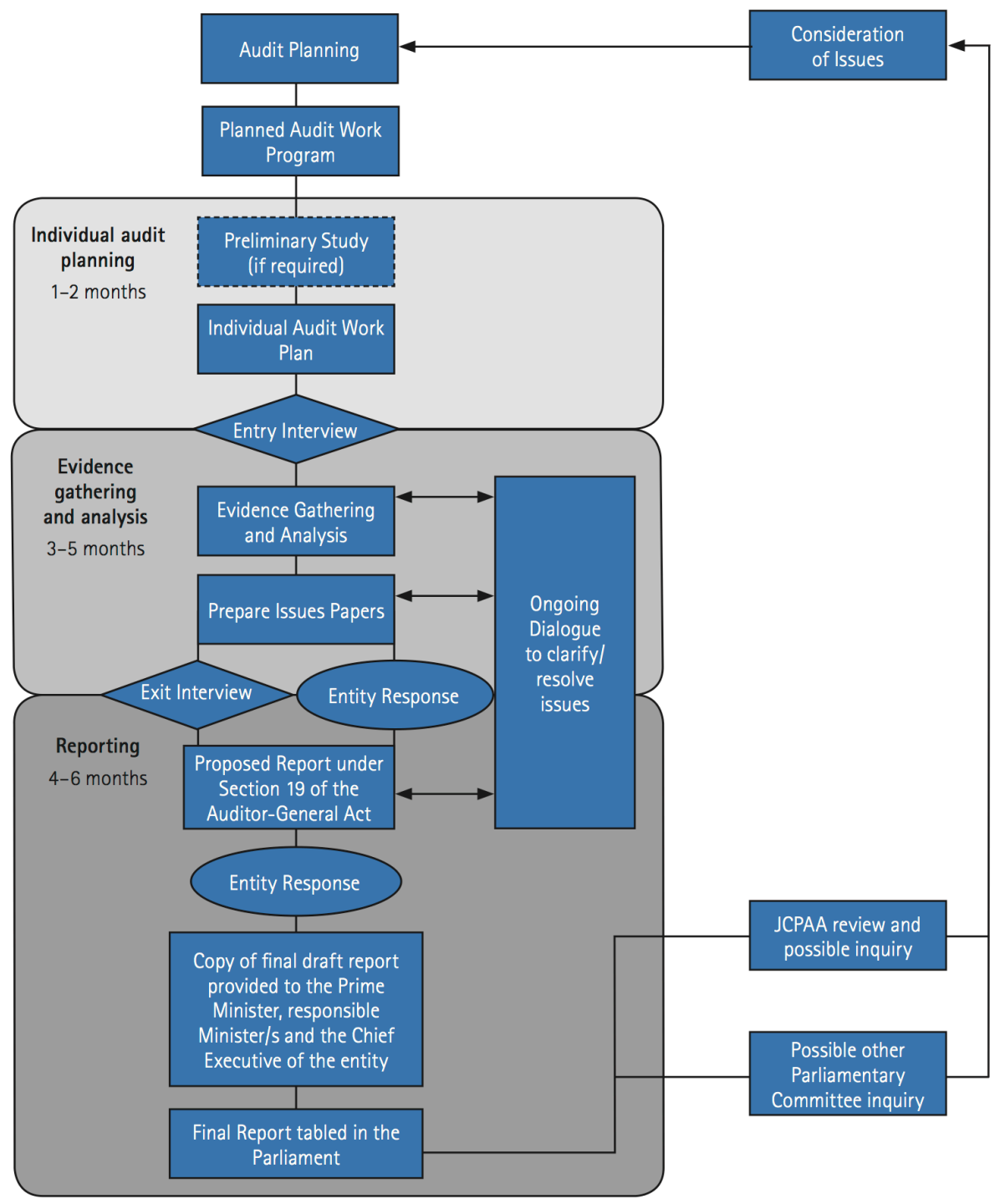

Figure 2: Standard performance audit process at the ANAO

Source: ANAO 2008, p. 5. 


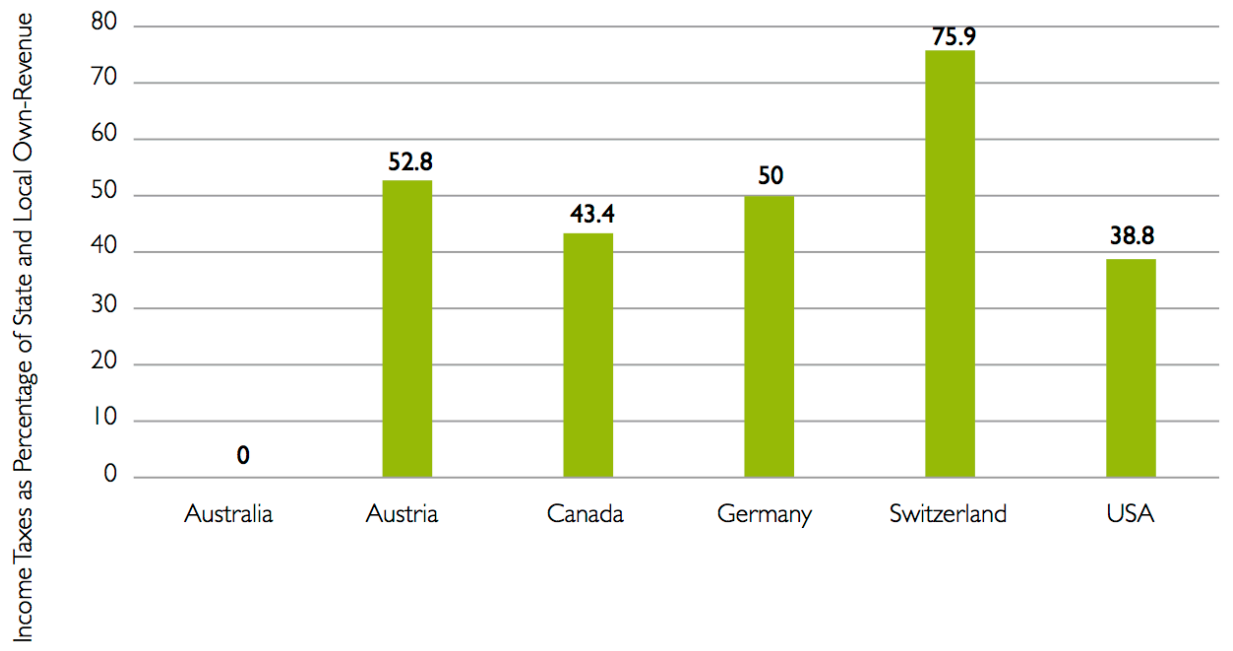

Figure 3: State government access to income taxes: Selected federations, 1965-2004

Source: Twomey and Withers 2007, p. 39.

To address this fiscal imbalance, states and territories in Australia are given significant annual financial support from the Commonwealth government, amounting to $\$ 97$ billion in 2011-12, about 25.7 per cent of the Commonwealth's total expenditure (Australian Government 2012). In some cases, transfers can be as much as 60 per cent of a state's total revenue (Quiggan 2005). Not surprisingly, such dependence has increased the Commonwealth's power and influence (Fenna 2008), producing a federation more centralised than originally intended (Podger and Wanna 2012). Some critics refer to this dynamic as 'opportunistic federalism', whereby the Commonwealth, 'picks and chooses State issues upon which to intervene for political purposes' (Twomey and Withers 2007, p. 28), effectively rendering the states as service delivery agents of the Commonwealth.

In 2009, the Council of Australian Governments (COAG) introduced reforms to address vertical fiscal imbalance-related issues including a commitment by the Commonwealth to provide ongoing financial support for states' service delivery in three ways, including general revenue assistance, National Specific Purpose Payments (SPPs) and National Partnership Payments (NPPs). The latter two payments are considered to be conditional grants because they are attached to a set of Commonwealth objectives, outcomes, outputs and performance indicators. Although performance reporting associated with the SPPs and NPPs is managed by the COAG Reform Council and the COAG Standing Council on Federal 
Financial Relations, prior to the 2011 amendments to the Auditor-General Act 1997, these payments were not subject to the oversight of the Commonwealth Auditor-General, nor by state level auditors.

Despite the financial framework reforms, federal financial transfers end up as services delivered by both jurisdictions. For example, responsibility for education services rests with the state governments, yet the Commonwealth makes contributions to education through its $\$ 9.7$ billion National Schools SPP. Since SPPs are attached to national policy objectives, the Commonwealth government is responsible for attaining these objectives, yet the accountability attached to the Commonwealth portion of the funds rests with states for proper management and reporting to the Commonwealth as to how the funds were spent.

\section{The JCPAA and the Inquiry into the Auditor-General Act 1997}

In 2009, the Inquiry into the Auditor-General Act 1997 (the Inquiry) was undertaken by the JCPAA. Representing the formal link between the Commonwealth Auditor-General and the Australian Parliament, the JCPAA is a parliamentary committee that informs the Auditor-General of the Parliament's audit priorities, recommends the resource levels for the ANAO (McPhee 2012), and regularly reviews the legislation to ensure it remains relevant in the modern public sector environment (ANAO 2012a). While the 2009 review was considered to be routine (eight years had passed since the previous one), its timing could not have been more opportune for the Auditor-General in light of the recent reforms to the federal financial relations framework.

One area the JCPAA was interested in reviewing was the Auditor-General's 'capacity to examine the financial and performance outcomes from Commonwealth investments in the private sector and Commonwealth grants made to State and local governments' (JCPAA 2010, p. xi).

Such access is often called 'follow-the-money' legislation, as it enables the auditors to follow the spending trail from end-to-end without being restricted once service delivery leaves the Commonwealth jurisdiction. References to 'follow-the-money' legislation often bundle together the ability to audit transfers to any third party or Commonwealth partner, including states and territories, private companies or NGOs. However, there is a significant difference between auditing contractors and auditing state and territory partners, and this issue figures prominently later on in this report.

In a submission to the Inquiry, the Institute of Public Administration of Australia made reference to the financial transfers to the states and territories, 
showing concern that 'the Commonwealth Auditor-General does not audit these programs against the agreed objectives, nor do state Auditors-General', and that 'states may report back on their claimed performance but the Commonwealth has no real check as to their validity and reliability,' (JCPAA 2010, p. 58). The Commonwealth Auditor-General confirmed the notion of the 'gap', explaining that the ANAO is 'constrained at the moment to look at state performance or the performance of grantees under [the] act, so it is a central issue' (McPhee 2010 , p. 8). An issue further compounded by the recent reforms to the federal financial framework, which relaxed the Commonwealth prescriptions on state service delivery (JCPAA 2010).

To address the cross-jurisdictional issues in the JCPAA's terms of reference for the Inquiry, the ANAO identified options in order of potential impact and preference:

- Full access powers to audit states and territories in receipt of transfers in circumstances where there is a corresponding or reciprocal responsibility to deliver specified outcomes in accordance with agreed arrangements'.

- The same as above, but rather than amend the Auditor-General's legislation, the powers could be provided via separate legislation governing SPPs.

- Make it mandatory that SPP legislation and agreements include access provisions for the Auditor-General - something already occurring on an ad hoc basis.

- Explore 'further cooperation between the Auditor-General and the state and territory Auditors-General', the preferred option of other stakeholders, such as the Australian Council of Auditors-General and the Institute of Public Administration of Australia (ANAO 2009).

Further cooperation meant pursuing cooperative audits between the Commonwealth and state auditors-general to address issues of mutual concern, in this case the federal transfers. However, the cooperative audit approach did not receive much discussion by the JCPAA after ANAO flagged the secrecy and information sharing provisions in the Act, different audit office priorities, and the challenges with synching performance audit cycles with each other, making the timing of the phases difficult to align.

\section{Resulting amendments and the new mandate}

In their final report, the JCPAA recommended enhancements to the mandate of the Auditor-General, including the power to conduct cross-jurisdictional performance audits of states and territories. By December 2011, Parliament had endorsed several amendments to the Act, which represented 'the most significant enhancement of the auditor-general's mandate since the addition of efficiency 
audit powers in 1979' (INTOSAI 2012a). The new legislation allowed for the audit of 'Commonwealth partners', a term used to group together any recipient or contractor receiving money directly or indirectly from the Commonwealth for a particular purpose. This includes state and territory bodies, but, in these cases, an audit may only be conducted at the request of the JCPAA or the responsible Commonwealth minister. However, the Auditor-General can ask the JCPAA or the responsible minister to request such an audit (ANAO 2012a).

The Auditor-General will need to employ this new power in a way that develops its legitimacy. However, performance auditing is often a high-profile activity. It is unclear what plans exist for conducting cross-jurisdictional performance audits, and what reactions might emerge from the states, territories, and other stakeholders.

\section{Summary of key stakeholder relationships}

Although the Auditor-General and the ANAO derive credibility from their independence and objectivity, the development of meaningful relationships is also central to the execution of the mandate. Such relationships can help to promote the value of the Auditor-General and the ANAO to the public sector, which points to the need to manage expectations (Wanna, Ryan and Ng 2001). What follows reviews key stakeholder relationships, including potential new ones which might emerge with the introduction of CJPAs and possibly some form of cooperative auditing.

\section{Parliament and the JCPAA}

As part of its regular operations, the ANAO 'provides briefings to ministers, shadow ministers, parliamentary committees and their staff on audit reports tabled in the Parliament' (Barrett 2002, p. 35) making the Auditor-General's relationship with Parliament a critical activity of the audit office. Despite the emphasis on the significance of independence, the Auditor-General's objectives can only be fully met with the 'trust and respect of the Parliament' (Barrett 2002, p. 45). By extension, this notion of trust also holds true for the AuditorGeneral's relationship with the JCPAA. The JCPAA must determine the audit priorities of Parliament, advise the Auditor-General of those priorities, and review all reports tabled by the Auditor-General in each house of Parliament. The JCPAA oversees the operations, resources and external audit of the ANAO, reporting to both houses on matters relating the Auditor-General's functions and powers they believe require attention. 


\section{Auditees: Departments and agencies}

A positive relationship with an auditee makes for a more efficient audit. Since 1995, the ANAO has considered auditees to be important stakeholders (Wanna, Ryan and Ng 2001). Cooperation is necessary and encouraged for building trust, adding value, maintaining credibility, and ultimately gaining 'genuine acceptance of [the ANAO's] recommendations' (Barrett 2002, p. 38).

Commonwealth-level departments and agencies could have a stake in the new CJPA process. Prior to CJPA access, performance audits were limited by restrictions to the assessment of Commonwealth level entities, and in the cases of transfers to states and territories, the ANAO could only comment on the performance of those Commonwealth entities in managing state and territory agents, and without access to state and territory files. The case for CJPAs flows from the idea of an end-to-end audit that includes access to the state and territory agencies as well as assessing management of services funded by the Commonwealth. CJPAs have the potential of revealing issues at the state and territory level which have not been seen and which could be detrimental to the Commonwealth departments as well as state and territorial governments.

\section{Executive coordinators (central agencies): Treasury, Finance, Prime Minister and Cabinet}

Wanna, Ryan and Ng (2001) describe the relationship between the AuditorGeneral and central agencies as one of ambivalence: they have a mutual interest in accountability, but the potential for exposure is a political risk. Risk is typically high because central agencies are 'active players with their own agendas and powers and have a major say in determining many of the circumstances under which the Audit Office operates' (Wanna, Ryan and Ng 2001, p. 247).

In the context of this report, the Commonwealth central agencies can be seen as having a vested interest in extending the powers of the Auditor-General in order to improve accountability for intergovernmental transfers, and, in particular, if they seek to shift the focus to the management and performance of states and territories.

\section{Professional bodies and international associations}

The ANAO maintains relationships with several domestic professional associations, including Chartered Practising Accountants Australia and the Institute of Chartered Accountants Australia, and makes contributions to developing accounting and auditing standards to the Australian Accounting Standards Board and the Auditing and Assurance Standards Board (ANAO 2012a). 
The ANAO is also a member of several international and regional institutions, with the primary purposes of information sharing, training and development, and setting of international standards. The most important among these groups is the International Organisation of Supreme Audit Institutions (INTOSAI), represented by 170 Auditors-General around the world. The ANAO sits on the Global Working Group, Professional Standards Committee, Performance Audit Subcommittee, and Working Group on Environmental Auditing (ANAO 2012a). INTOSAI is a venue where offices can share ideas and promote better practices. The introduction of CJPAs could have an impact internationally if Australia is deemed an innovator in auditing of intergovernmental transfers.

\section{Media, academics, commentators and the public}

The media often plays a role in highlighting the ANAO's work. Although the ANAO maintains a public website containing its reports and better practice guides, the extent of media coverage depends on what is said in Parliament. The media can play a major role in shaping public perceptions about the quality of the programs and services of the Commonwealth, as well as those of academics and other commentators. Ultimately, the Auditor-General and the ANAO aim to improve public administration, and it is important to maintain links with the media and to the public. Academics and other sector specialists can also assist the Auditor-General (Lonsdale 2008), especially when there is a need for expertise in certain issue areas that is not available in-house.

The addition of CJPAs to the Auditor-General's mandate could influence the public. As voters, they elect different representatives to the Commonwealth and state and territory governments, creating two chains of accountability. Changing how accountability works or increasing transparency of operations could impact the public's perception of both levels of government and ultimately confidence in the political process, perceptions of the quality of public services, and even voting behaviour.

\section{ANAO (internal relationships)}

Internally, the Auditor-General has one stakeholder: ANAO staff. The Performance Audit Services Group will be the most impacted by the new legislation, but the entire office could also be influenced because a new set of program activities may affect resourcing, staff experience, planning, and timing of audits. The CJPA approach may affect the performance audit process at each of the stages. 


\section{New stakeholder relationships post-amendments}

Figure 4 depicts the external stakeholder relationships that may arise at the state level if the Auditor-General moves forward with CJPAs and possibly cooperative audits.

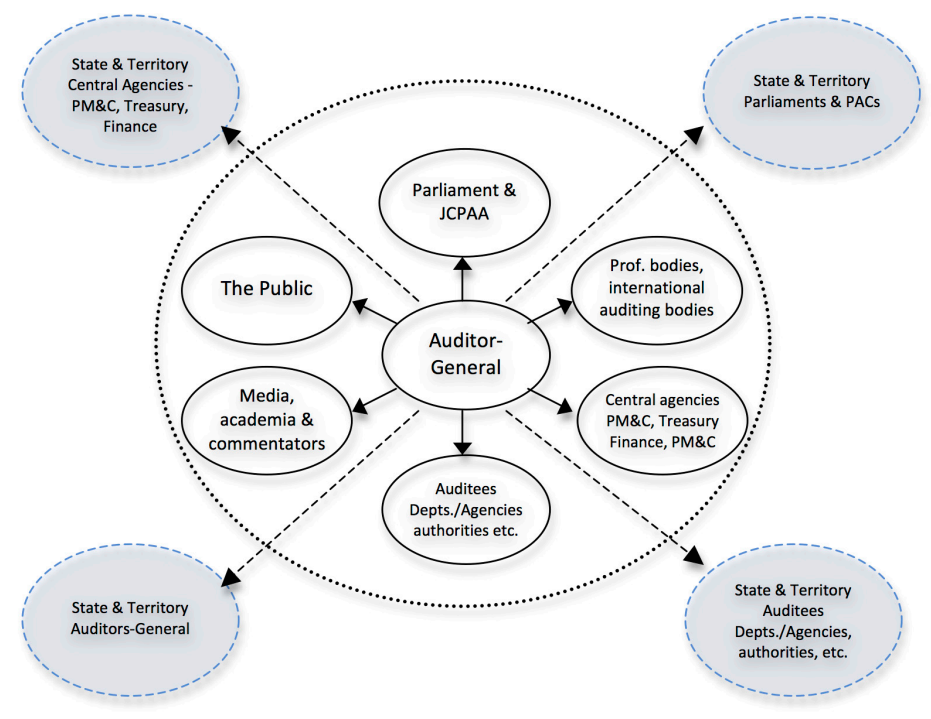

Figure 4: Anticipated stakeholder relationships of the Auditor-General during CJPAs

Source: Adapted from Wanna, Ryan and Ng 2001, p. 230.

\section{State and territory auditors-general}

All six states in Australia have Auditors-General, as do the Northern Territory and the Australian Capital Territory. Until recently, contact between these auditorsgeneral has occurred primarily at the bi-annual meetings of the Australasian Council of Auditors-General. ${ }^{3}$ The Commonwealth Auditor-General occasionally contacts auditors-general in other jurisdictions, but separate jurisdictional mandates and responsibility to different parliaments tends to discourage such contact.

The introduction of CJPAs and possible cooperative audits could significantly affect state and territory auditors-general. There could be an increase in time demands from the Commonwealth Auditor-General not only through consultation and information sharing, but because of the potential impacts on

3 The Australian Council of Auditors-General includes members from Fiji, New Zealand and Papua New Guinea. 
their own performance audit programs. Commonwealth CJPAs may stir state and territory parliamentary interest in a topic not previously identified in their annual audit work programs. It is possible that the new legislation for CJPAs might force more interest by the state and territory auditors-general into cooperative audits in order to keep the Commonwealth Auditor-General out of their turf. Again, this would serve to shift state and territory audit priorities.

\section{State and territory parliaments and PACs}

Although state and territory parliaments and public accounts committees (PACs) may not be directly impacted by CJPAs, indirect impact may occur depending on the audit topic. If a CJPA has significant outcomes at the state and territory level, the respective parliaments might take notice and demand action or further investigation by state or territory governments or their respective auditorsgeneral. CJPAs could also induce the state and territory auditors-general to pursue more cooperative audits with the Commonwealth Auditor-General, potentially diverting attention from previously identified state and territory audit priorities.

\section{State and territory executive coordinators: Treasury, Finance, Premier and Cabinet}

The states and territories are inextricably linked to the Commonwealth government, due to financial transfers. State governments have always had an interest in the accountability arrangements for intergovernmental transfers with respect to whether the Commonwealth was spending its own money efficiently and if it had 'handed over the due surpluses' (Wanna, Ryan and Ng 2001).

However, the introduction of CJPAs could change this relationship if the states and territories feel threatened by the new powers, particularly when audits leave them exposed or portrayed negatively. Mere access alone is enough to cause friction in light of historical mistrust between the states and territories and the Commonwealth, and explains the frequent references to sovereignty and constitutional rights when CJPAs were a prospect. Conversely, there is potential for positive outcomes for the states and territories from CJPAs in cases which might expose Commonwealth mismanagement or at best invite changes to the often-criticised restrictions and prescriptions placed on the transferred funds, which can result in perverse spending by the states and territories. 


\section{State and territory auditees: Departments and agencies}

State and territory departments and agencies will be a new stakeholder for the ANAO, and sentiments could be similar to those of the executive and central agencies when conducting CJPAs. As Commonwealth auditors approach state and territory departments for information, it is unclear how they will be received. Will state and territorial audit offices be expected to give advice to the departments and agencies they ordinarily audit? Will these departments and agencies simply see the ANAO as another audit office? Another set of issues will arise once issues papers are shared for review and reports released to Parliament and the public for consideration. At the very least this raises critical issues about whether and how to foster trust in such potentially difficult terrain.

\section{Literature review}

The literature review focuses on academic and professional literature relating to the emergence, development, process, application and impacts of performance audit, including its various external influences and modern day challenges. Literature on the emerging use of cross-jurisdictional and cooperative approaches to performance audit is reviewed and a conceptual framework developed to illustrate how CJPAs might impact the standard performance audit process at the ANAO.

\section{Origins and growth of performance audit}

As recent as 2011, literature on performance auditing has been described as 'underdeveloped' (Furubo 2011), and much of what is available is often focused on the qualities it shares with the field of evaluation (Chelimsky 1985; Leeuw 1996; Pollitt and Summa 1996; Pollitt et al. 1999). While there is general acceptance that performance audit has drawn considerably from the field of evaluation, particularly in the development of its methods (Lonsdale et al. 2011), this has not precluded a broad discussion of performance audit as a unique practice.

Performance audit (known also as efficiency audit and value-for-money audit) first emerged the United States in the 1920s with the establishment of the General Accounting Office (later Government Accountability Office), who had been tasked with investigating and making recommendations to Congress on greater economy or efficiency in public expenditures (Budget and Accounting Act of 1921, Sec. 312(a), 42 Stat. 25). However, performance audit began to emerge more significantly in the 1970s as a distinct practice with statutory backing at audit offices around the world, including Canada, Australia, the United Kingdom, and parts of Western Europe and Scandinavia (Pollitt et al. 
1999). From seemingly humble beginnings, contemporary performance audit now takes its place as a key area of the overall audit functions carried out by auditors-general (see Figure 5).

\section{Mandate}

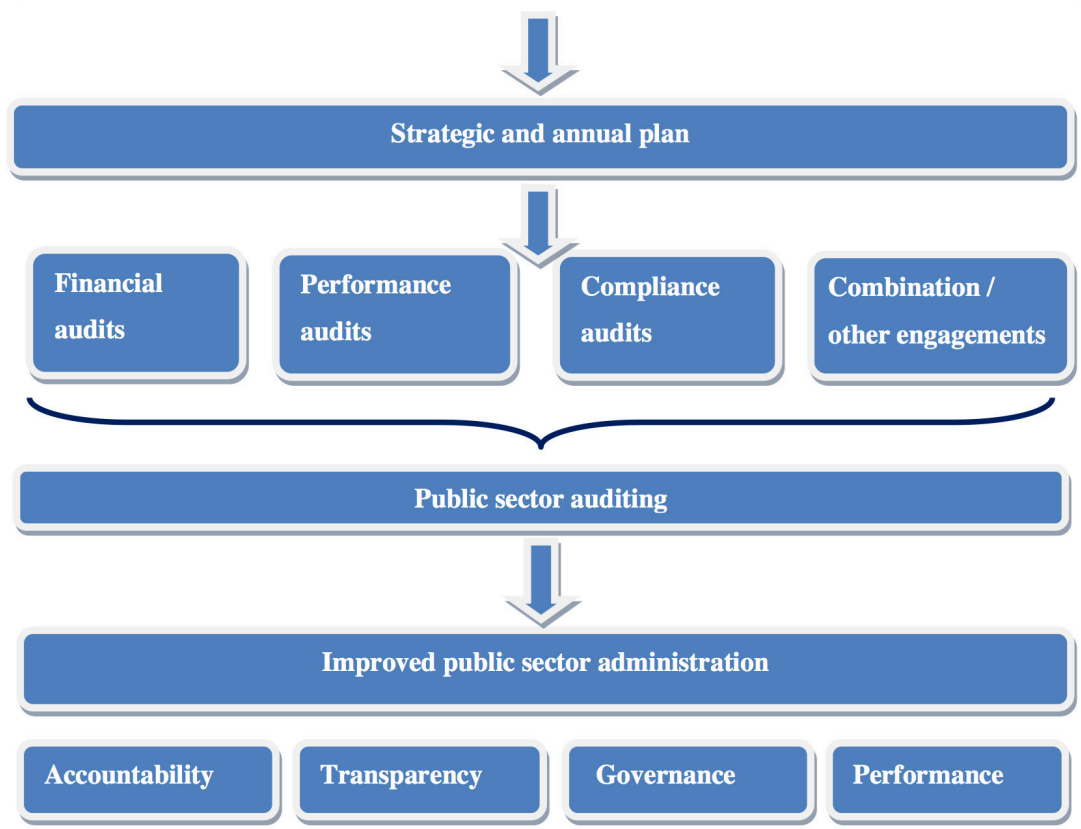

Figure 5: Role of performance audit in broader scope of activities conducted by supreme audit institutions (SAls)

Source: INTOSAI 2012b, p. 8.

\section{Performance audit and accountability}

The notion of the inadequacy of traditional forms of audit (English and Guthrie 2000) and the subsequent emergence of performance audit, is widely recognised as a direct consequence of the widespread administrative reforms that swept across the public sector in the 1970s under 'new public management' (NPM) (see Aucoin 1990; Pollitt and Summa 1995; Leeuw 1996; English and Guthrie 2000; Gendron et al. 2007; Funnell and Wade 2012). As the reforms placed a new emphasis on 'leaner government, better service delivery, and more efficient and effective management of government programmes' (Funnell and Wade 2012, p. 435), the rules-based and process-driven routines of the past were gradually replaced with a more results-based accountability, focused on identifying desired outcomes, setting performance targets for the public service, and measuring the extent of achievement of those targets (Aucoin 1990; Hood 1991; Pollitt and Summa 1995). 
Barzelay (1997, p. 235) saw the take-up of performance audit by external audit institutions as an action rationalised by NPM, while Power (1997, p. 7) suggested it represented a whole new system of values, which he referred to as the 'audit society'. Given their shared concern with efficiency and effectiveness of public spending, the strong links between NPM and performance audit are not that surprising, having been described by another author as a 'mutual codependency' (English and Skaerbaek 2007, p. 239).

The literature generally supports the notion that performance audits make a unique contribution to public sector accountability. For example, Pollitt (2006, p. 48) points to the ability of performance audit reports to 'command political attention', due in part to their mandatory review by parliamentary committees. Similarly, Lonsdale et al. (2011) sees performance audit reports as accountability mechanisms in their own right - the public availability of their reports offers citizens a rare window into the actual management of government operations. In Australia, Funnell (1996) and Funnell and Wade (2012, p. 447) have described performance audit as a 'source of institutional pressure, exerted on the Executive on behalf of the Parliament to account for the efficiency, effectiveness and economy with which it manages and uses public resources'.

\section{Performance audit in practice}

The academic and grey literature identifies two chief purposes of performance audit (Barzelay 1997; Pollitt and Summa 1996; Lonsdale 2000, INTOSAI 2012b). The first is to provide oversight and scrutiny of government spending, which links to the accountability and transparency aspects of governance. The second, a more recent development, is to improve public administration, or more specifically, the management practices of public sector managers.

The objectives of performance audit have been articulated in many ways, depending upon the supreme audit institution (SAI), its mandate, legislation, and resource capacity. Objectives for individual audits are usually expressed in one overall question or statement that the audit will address and can also include financial and compliance components. Auditing standards developed by INTOSAI (INTOSAI 2012b) set a baseline for the kinds of objectives an individual performance audit ought to have, including the three 'Es' often referred to by SAIs. These include an examination of one or more of the following assertions:

- Economy of activities in accordance with sound administrative principles and practices, and management policies. The principle of economy is about keeping the costs low. The resources used should be available in due time, in appropriate quantity and quality and at the best price. 
- Efficiency of utilisation of human, financial and other resources, including examination of information systems, performance measures and monitoring arrangements, and procedures followed by audited entities for remedying identified deficiencies. The principle of efficiency is about getting the most from available resources. It is concerned with the relationship between resources employed, conditions given and results achieved, in terms of quantity, quality and timing of outputs or outcomes.

- Effectiveness of performance in relation to the achievement of the objectives of the audited entity, and the actual impact of activities compared with the intended impact. The principle of effectiveness is about meeting the objectives set. It is concerned with attaining the specific aims or objectives set and/or achieving the intended results. Where appropriate, the impact of the regulatory or institutional framework on the performance of the entity should also be taken into account (INTOSAI 2010, p. 2; INTOSAI 2012c, p.4).

\section{Process and methods}

Despite early views of performance audit as merely a technical discipline (Adams 1986), there has since been consistent attention paid to the variability and non-standardisation of performance audit in practice (Glynn 1985; Guthrie 1987; Hamburger 1989; Barzelay 1997; Pollitt et al. 1999). Hamburger (1989, p. 4) disagreed with the presumed objectivity of the technical performance audit, believing that, 'far from being a neutral, technical discipline, performance audit is what the auditors choose to make it'. Likewise, others have highlighted that the application of performance audit depends upon the context and the subject matter (Pugh 1987; Guthrie 1989), ultimately subject to influences of social and organisational factors (Guthrie 1989). More recently, the literature seems to have accepted this variability in application as a positive feature, referring to the benefits of its 'fluidity', 'malleability' and 'flexibility' (Jacobs 1998; Guthrie and Parker 1999), as what makes performance audit so unique (Justesen and Skaerbaek 2010; Funnell 2011; Kells 2011; Lonsdale et al. 2011). This flexibility in application is also supported in the contemporary professional literature, including implementation guidelines issued by INTOSAI (2004), which stipulate that

performance auditing is complex investigatory work that requires flexibility, imagination and high levels of analytical skills. Streamlined procedures, methods and standards may in fact hamper the functioning and the progress of performance auditing. Consequently, standards as well as quality assurance systems - that are too detailed should be avoided (p. 29). 
Despite all the variations that may take place, there are some consistencies in practice. Many SAIs use the INTOSAI guidelines as their program foundation, followed by their individual system constraints, such as mandate and resourcing. The first step in a performance audit is the preliminary phase of topic selection. INTOSAI (2012c, p. 3) recommends that performance audit topics 'should aim to maximise the expected impact from the audit while taking into account audit capacities', which can be done by giving due regard to audit problem and or risk assessment and materiality of significance (including financial, social or political significance). Pollitt et al. (1999) identified five common selection factors: cost of the audit; the risk to public funds; coverage of the greater audit field; follow-up of earlier topics that had identified problems; and topics with high political attention.

Once topics have been approved, they go through roughly the same three phases: audit planning, conducting, and reporting (See Figure 6).

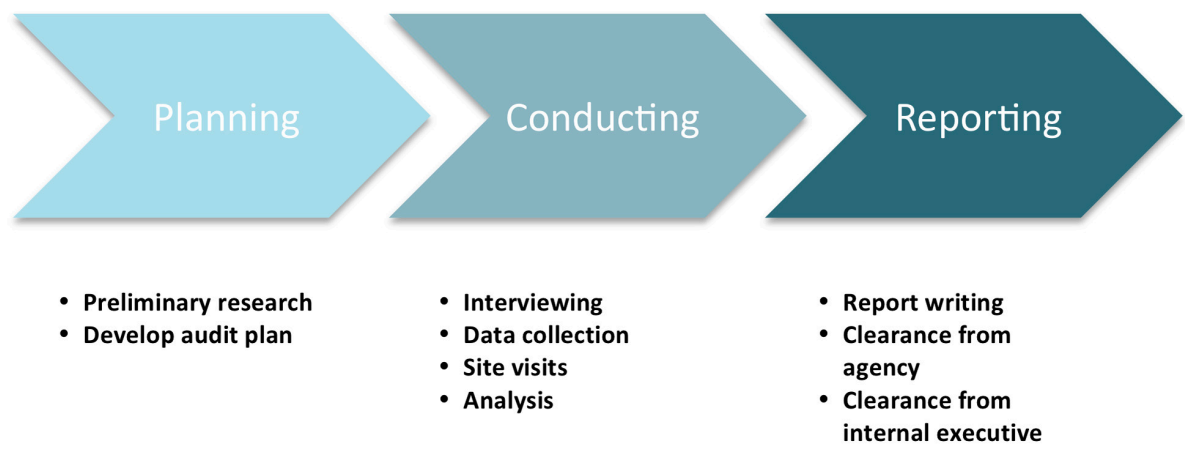

\section{Figure 6: Typical phases of the performance audit process}

Source: Adapted from various performance audit manuals in Canada, Australia, and the UK.

- Audit planning: The planning phase includes development of background information, risk assessment, possible evidence sources, feasibility, significance/materiality, objective, scope, methodology, resource requirements (including staff numbers and skill sets), estimated cost, and audit timeline.

- Conducting: The conducting phase consists of the collection and examination of the data sources as outlined in the planning phase. The nature and extent of audit evidence required for the audit is driven by the topic and the objective. Typically there is a variety of evidence collected — including physical, documentary, testimonial or analytical - the relevance of which should be explainable and justifiable. All findings and conclusions must be supported by audit evidence. Data is often sought from sources and stakeholders other 
than the auditee to provide a more complete picture. Analysis of all data collected also occurs in this phase.

- Reporting: The reporting phase involves the write up of the analysis conducted by the auditors. Each report is unique and they often vary considerably in scope and nature amongst SAIs. Reports include information about the objective of the audit, the methods, scope, criteria, data sources and findings. Findings make clear conclusions and if necessary include recommendations. All relevant viewpoints are to be considered and reported in a balanced fashion. Unless prohibited by their mandate, SAIs should always give the auditee the opportunity to comment on the audit finding, conclusions and recommendations - this process is often referred as the 'clearance process' (Sharma 2007; Lonsdale 2008) or as extending the principles of natural justice (INTOSAI 2010, p. 3-7).

\section{Pressures and influences}

The practice of performance audit does not happen in isolation. The process has both an influence on, and is influenced by the outside world. According to Lonsdale (2008) and others (Pollitt et al. 1999), these influences or pressures can have an effect on the actual conduct of the audit work. Pollitt and Summa (1999) have developed a conceptual model to represent how the basic performance audit process of an SAI is subject to various external influences, as well as to indicate how performance audit reports can make impacts on their greater operating environment (see Figure 7). Developments in public management outside of the audit environment can have impacts on how performance audits are organised internally. Likewise, recommendations from performance audit reports can result in changes in the management practices of public agencies or departments (Pollitt et al. 1999). Changes to any one element of this process can result in flow-on effects to any or all of the stakeholders involved.

\section{Relationships}

Several authors in the performance audit literature have referred to the conflicting demands placed on auditors by their various stakeholders. Put and Turksema (2011, p. 51) describe the role of an auditor as a constant 'balancing act between listening to stakeholders and safeguarding their independent position', while Wanna, Ryan and Ng (2001, p. 229) point to the inevitability that each of these stakeholders will have different expectations and perceptions of the auditors based upon the nature of each of these relationships. For the government bodies or auditees, the audit needs to be useful, and to be a learning experience for them. At the same time, Parliament is also considered a main 
client of most SAIs, and therefore their focus is 'much more on performance compliance and transparency, and where independent opinions are considered of prime importance' (Put and Turksema 2011, p. 52).

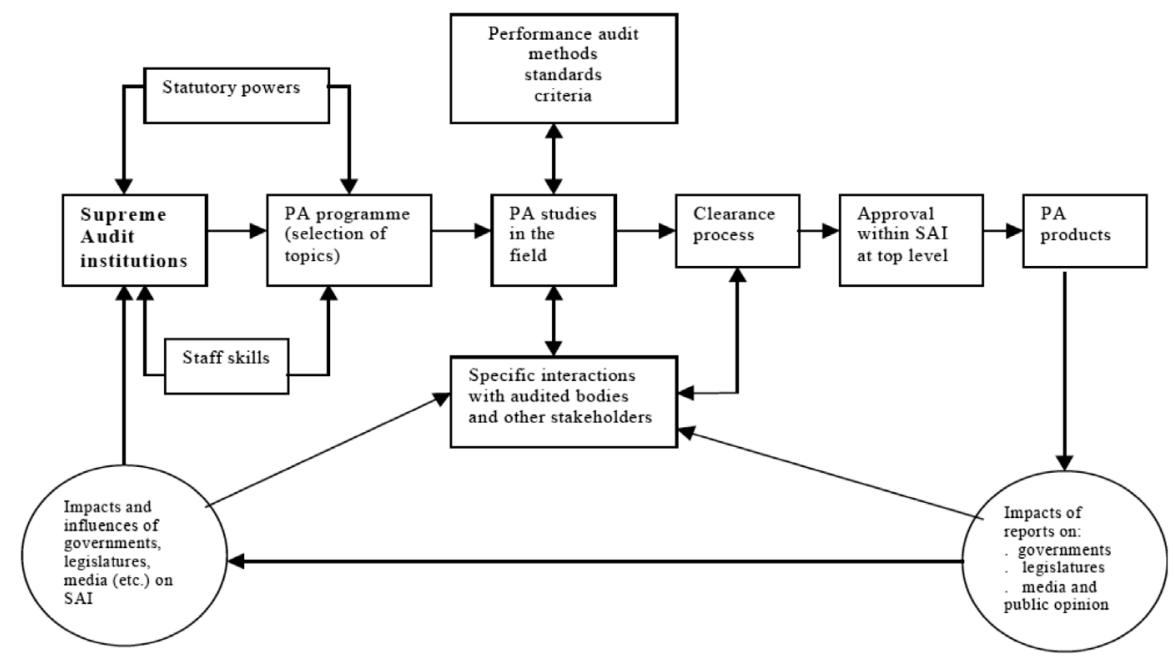

\section{Figure 7: Influences on the performance audit process}

Source: Pollitt and Summa 1999, p. 8.

The implications of poor stakeholder relationships in Australia have been long documented by Funnell $(1998,2003)$ and others (Taylor 1996; Guthrie and Parker 1999; English and Guthrie 2000; Lonsdale 2008), particularly with respect to attempts by the executive government in Australia to limit the intrusions of performance audit by 'attacking the reputations of auditorsgeneral and their staff' (Funnell and Wade 2012). Funnell and Wade (2012) cite similar instances in other countries such as the UK and Canada, where their executives have attempted to undermine audit credibility through a variety of measures including:

limiting their resources, challenging their mandates and denigrating the quality of individual reports, accusing the auditors of blinkered naivety which leads to incomplete findings, and an alleged tendency to encroach on policy issues (Funnell and Wade 2012, p. 439; see also Sutherland 2001).

The relationship between auditors and auditees is also well documented in the literature (Keen 1999; Morin 2001, 2008; Sharma 2007; Talbot and Wiggan 2010; Funnell and Wade 2012). Keen (1999, p. 522) highlighted the amount of negotiation required between auditor and auditee and the inevitability of 
their disagreement due to different belief systems and assumptions. Similarly, Morin (2001, p. 115) has observed the complexity of the relationship, 'where perceptions of reality outweigh reality itself, where power plays occur and where the reactions of both parties are quite unpredictable'. More recently, Funnell and Wade (2012) have summarised the 'persistent problems' between auditors and auditees at the ANAO over the years, and found that much of the tension results from a difference of interests and perceived value. Auditors have an interest in the 'survival and growth' of performance audit and believe in its ability to add value to public administration, while auditees tended to view the practice in a negative light, and question the credibility of the practice in an attempt to 'protect themselves and their agency' (Funnell and Wade 2012, p. 446). Despite some evidence of auditees responding with compromise, Funnel and Wade (2012, p. 447) document the 'overwhelmingly ... resistant forms of tactical behaviour ... especially those associated with the strategic responses of defiance and manipulation'.

Other external relationships include those with academics, consultants and specialists who provide the Auditor-General with sector specific or technical knowledge on some audits. Many audit agencies - including the Office of the Auditor General of Canada and the UK National Audit Office - access experts with reference or expert panels (Lonsdale 2008), perceived as playing a 'major part in the development of VFM [value for money] quality assurance processes' (Lonsdale 2008, p. 236). Academics, for example, often assist agencies in developing performance audit methods as well as in clarifying the links between evidence and conclusions (Lonsdale 2008).

\section{Impacts}

Clearly relationships play an important role in the performance audit process, and many SAIs have taken efforts to improve these relationships based upon the belief that they will result in more positive impacts. Often this is done through follow-up audits, where auditors check to see whether earlier recommendations were followed (Pollitt et al. 1999; van der Knaap 2011), but others take measures on the front-end of an audit to encourage uptake of the entire process. In Australia for example, the ANAO commits itself to a 'no surprises' approach to performance audits:

The ANAO seeks to establish a relationship with entities and other parties such that there are 'no surprises' in the final audit report. This approach provides opportunities for entities and other parties to discuss the audit findings during the course of the audit. The benefit of this approach is to ensure that reports are accurate, evidence-based, balanced and fair. (ANAO 2012a, p. 8) 
This approach has been further supported by a shift in focus from government waste and program failures - sometimes referred to as 'gotcha' audits - to reports focused on opportunities for learning and the promotion of better practices (Barrett 2011). Lonsdale (2000; Lonsdale et al. 2011) observed this shift in focus as a move towards the notion that performance audits ought to 'add value' to the greater world of public administration and management, by 'identifying better ways of doing things' (Lonsdale 2000). Part of this was accomplished by shifting the timing of performance audits from an almost exclusively ex post approach to one that included the commencement of audits during the implementation of programs, the idea being that early intervention would help identify better practices as the programs rolled out and result in better impacts. In addition, some SAIs now develop their audit recommendations so that lessons learned can have a broader application beyond the audited department, while others develop stand alone better practice guides, which provide generalised advice on range of topics affecting public sector managers. ${ }^{4}$

Empirical studies that measure impacts have long been highlighted as a deficiency in the performance audit literature by several authors, including Wilkins (1995), Lonsdale et al. (1999), Morin (2001, 2008), and Barrett (2011). As one Auditor-General in Australia has observed, 'it's the holy grail for us that we all try to work out. You can see things change, and for the better, but trying to measure it is very difficult'. Barrett (2011) has echoed this sentiment and places emphasis on the achievement of identifiable outcomes for performance audit as a better way to measure impacts.

4 For examples, refer to the ANAO website at www.anao.gov.au, the NAO website at www.nao.org.uk, or the GAO at www.gao.gov 


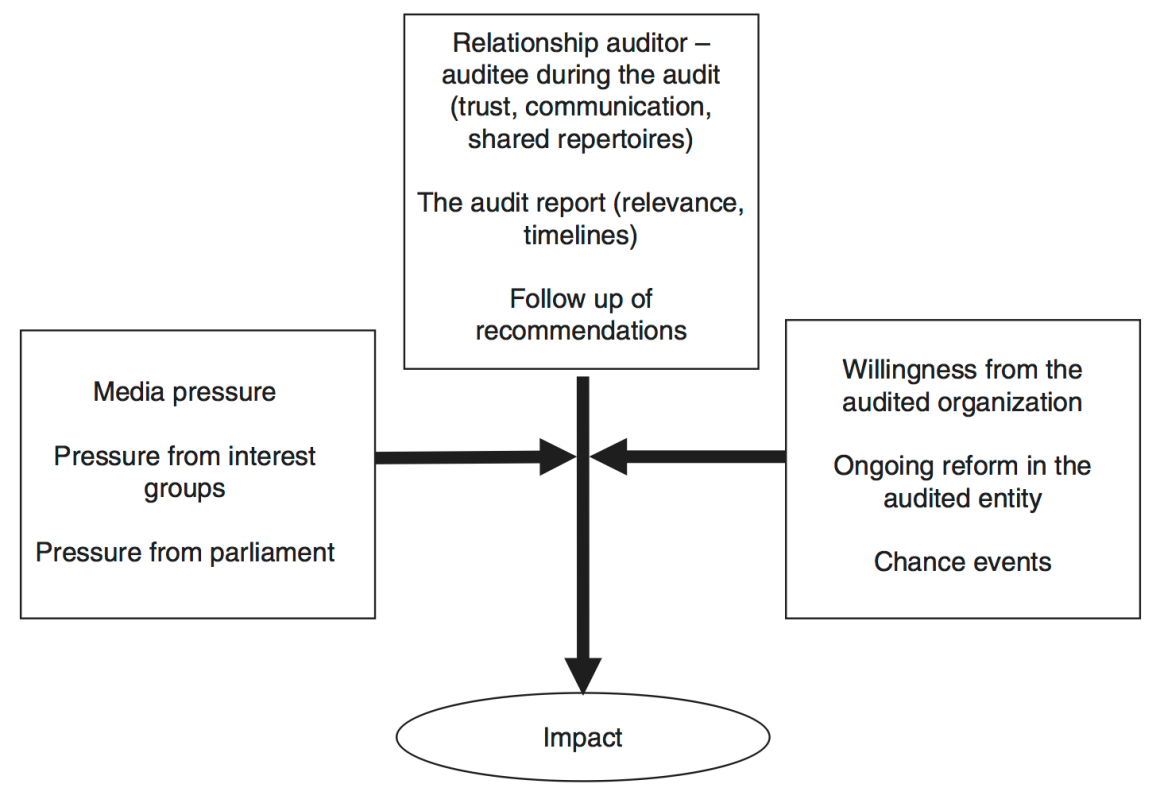

\section{Figure 8: Factors that determine the impacts of performance audits}

Source: Van Loocke and Put 2011, p. 202.

The most comprehensive study on impacts to date (Van Loocke and Put 2011), develops a framework for reflecting on the factors that influence audit impacts, and poises the field for further study in this area (See Figure 8). The study found that while performance audits do elicit positive impacts, they reaffirm Pollitt et al.'s (1999) earlier observation that these impacts are difficult to measure due to the inability to isolate cause and effect. While Pollitt et al. (1999) did outline several impacts including changes and improvements to public administration, cost-savings, and promotion of better practice, Van Loocke and Put (2011, pp. 202-203) identified four ways to improve upon those impacts: optimising the auditor-auditee relationship; managing its reputation through 'advocacy coalitions' with research institutions and media; investing more resources into audit selection and planning to boost audit relevance; and improving efforts to disseminate results and consult with relevant stakeholders.

\section{Critics}

The practice of performance auditing is not without its critics. Authors have accused the practice of having various deficiencies and, in some cases, as having adverse effects (Sutherland 1986, 2001; Pollitt et al. 1999; Shand and Anand 1996; Bowerman et al. 2003) or even no effect (Morin 2001). Performance audits 
typically increase the workload of audited agencies, creating inefficiencies (Pollitt et al. 1999), but some authors have suggested that they can actually cultivate negative behaviour changes in public managers, such as making them more risk-averse or anti-innovative. In the early days of performance auditing, some critics complained that the lack of standards and 'obscurity of methods' made it difficult to trust the findings as reliable (Sutherland 1986; 2002 p. 23), supposedly because it is based upon a subjective and 'utopian framework' (Clark and Swain 2005, p. 460). In a recent review, Kells (2011, p. 390) summarised many of these criticisms raised over the years into seven main categories of performance audit behavior: promoting anti-innovation; being too nit-picky; creating an expectations gap; behaving as a lapdog; encouraging unnecessary systems; hunting headlines in the media; and performing a hollow ritual. From Kells' (2011) perspective, each of these criticisms should be considered as a risk that can be managed in the design and operation of the audit institutions themselves, and Kells discusses several approaches to doing so. In other words, performance auditing is challenging work, but so long as risks are managed, the outcomes are ultimately good.

\section{Current challenges to performance audit and recent trends}

Although performance audit owes much of its existence to the cultural changes driven by the NPM reforms, its application has been ironically or paradoxically limited (Hood and Peters 2004) by many of the new forms of public sector management that emerged under these same conditions. The rise in privatisation, outsourcing and joint ventures for the delivery of public services are all well known to have challenged traditional accountability relationships in government. For auditors-general, their legislative powers of access were designed during a time when public services were delivered in-house by governments, and who have since been cut out from accessing or assessing the performance of government's partners in public service delivery, including when those partners are the departments of state and territories governments. Murray (2011, p. 131) explains that the problem is that 'third parties have been spending the money, but the Commonwealth has been carrying the risk', which means that Parliament is unable to obtain a full picture of how public services are being delivered.

This process is often referred to as an 'erosion of mandate' and cited as the reasoning behind the need for amendments to auditing legislation. The need to close such accountability gaps has been highlighted by auditors-general for many years, and has been well documented in the literature (see Funnell 1997, 2003). In a report commissioned by the Victorian Auditor-General's Office, Robertson (2009, p. 14) argued that the mandates of Auditors-General, 'should, 
de facto, be empowered to audit the use of public moneys, resources, or assets by any recipient or beneficiary regardless of its legal nature', and that any ability to 'circumvent' those powers ultimately undermines their purpose.

In Australia, requests to close this gap had been refused by successive governments (Barrett 2010), and even when access came it proceeded only incrementally. For example, GBEs were not audited until the most recent amendments in 2011. However, as Barrett (2010, p. 272) explains, 'even with reasonable access to premises and records, there is limited opportunity for performance auditors to establish 'value' either in the delivery processes or in the outcomes being achieved'.

\section{Cooperative performance audits}

Cooperative performance audits are an emerging concept in government auditing as a way to address inter-jurisdictional issues. Only limited academic and gray literature can be found on the subject, typically on government and professional association websites, or as the performance audit reports themselves. Initial reviews of the available documents reveal an inconsistency in cooperative audit terminology by various SAIs and academics, so the emphasis here is placed primarily on two guidance documents obtained from INTOSAI $(1998,2007)$. Several working definitions of the types of cooperative audits are drawn out, and are applied in a performance audit context.

A cooperative performance audit can be defined as an audit involving two or more audit institutions (INTOSAI 2007). ${ }^{5}$ There are three main types of cooperative audit including concurrent, coordinated, and joint, with each involving varying degrees of cooperation between the audit institutions involved and outlined below.

- Concurrent audits: Also known as parallel audits, a concurrent audit can be defined as an audit conducted simultaneously by two or more audit agencies, after agreeing on a common issue to audit. Concurrent audits use separate audit teams from each agency and table separate reports only to their own legislature. The findings and recommendations contained in the reports are only those relevant to the agency's own government. The independence of each agency involved in a concurrent audit means that each may adopt a different audit approach, including different criteria, scope, and methods, in order to accommodate the needs of each jurisdiction. The extent of ideas and experiences exchange often varies.

5 Some audit agencies and organisations use the term 'collaborative' in place of 'cooperative'. For the purposes of consistency, this report will refer to 'cooperative audits' as the catch-all term. 
- Coordinated audits: A coordinated audit falls somewhere in between concurrent and joint audits, and in practice tend to have a wide variety of configurations. Often there is some kind of collaboration in the planning stages of the audit, but agencies still operate with separate audit teams. Other examples include a joint team with separate reports, or concurrent audits with joint and individual reports.

- Joint audits: A joint audit is an audit conducted by a single audit team composed of auditors from two or more audit agencies. A joint audit involves a much greater degree of involvement between the two agencies and results in preparing a single audit report tabled in the legislatures of each participating jurisdiction. In practice, joint audits are rare.

Based on guidelines from INTOSAI $(1998,2007)$, these variations can be best illustrated on a spectrum from less to more cooperation, as presented in Figure 9. There are various audit elements that offices can cooperate on, including audit planning, developing criteria and methodology, sharing information, and sharing audit activities (such as client interviews or report writing). As more of these elements are shared, the more integrated the cooperation becomes.

Interest in cooperative auditing arose primarily out of the desire of SAIs to audit compliance with international environmental accords and other treaties and agreements that span multiple jurisdictions. For the agencies involved, 'cooperative audits facilitate mutual sharing and learning, capacity building, networking, and identification of best practices' (INTOSAI 2007, p. ix). At the same time, cooperative audits may offer a more complete picture of the issue or program examined by including information about performance from other jurisdictions that would otherwise be left out of a traditional audit - sometimes described as an 'end-to-end' audit (McPhee 2012).

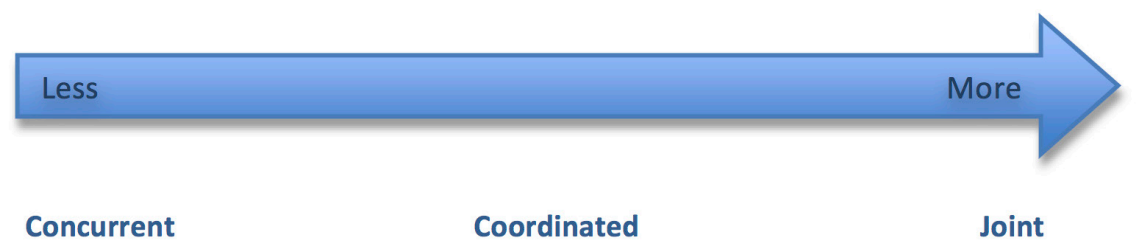

\section{Figure 9: Cooperative auditing from less to more integration}

Source: Author's research.

The opportunities of cooperative audits outlined by INTOSAI and some auditorsgeneral are echoed in the few academic articles that were located in the literature. Van Leeuwen (2004) argues that joint audits are the preferred approach because 
they have the potential for better quality and impact than a single audit alone. Likewise, Mayne (2010, p. 4) believes that joint approaches make the most sense when auditing federal-provincial programs in Canada, because 'this matches how the programs are being delivered and would be a more cost-effective way of auditing the joint program than having separate federal and provincial audits being undertaken, likely at different points in time'.

In his writing about auditing in Australia, Nicoll (2005, p. 70) observed that the lack of joint audits was 'surprising given the potential benefits to all levels of administration from cooperation in planning, especially in light of the limited resources available for performance auditing and the importance of services funded through these programs'.

There are also challenges associated with cooperative audits, many of which have been identified by auditors after taking part in cooperative audits. Mayne (2010, p. 4) admits that performance audit practices can vary significantly among audit offices, making cooperative work challenging, not to mention the value placed on independence by audit agencies, which is 'tightly guarded'.

When choosing a type of cooperative audit to undertake, INTOSAI guidelines recommend that primary consideration should be given to the availability of resources and time, the competency and experience of staff, and general knowledge base of each agency. The approach used also might depend on the topic of the audit and the priorities of each jurisdiction. While concurrent audits only require enough consultation between audit offices to set a topic, scope, and possibly a rough timeline, this approach lacks integrated conclusions, and therefore may have less impact for legislators. In contrast, joint audits are comprehensive, integrated, and have the potential for significant impacts; but there are many practical challenges stemming from jurisdictional differences. Finally, coordinated approaches are the most flexible, and can be altered to suit the degree of integration desired by both parties. Ultimately, successful cooperative audits require the commitment of both jurisdictions because 'whatever type of audit is chosen, the parties involved must have a sincere desire to cooperate with one another for a common purpose' (INTOSAI 1998, p. 19).

\section{Cross-jurisdictional performance audits}

In the most general sense, a cross-jurisdictional performance audit (CJPA) can be defined as an audit conducted by a single audit agency of an entity that lay outside the audit agency's typical jurisdiction. This type of audit can be used to assess the performance of an entity in receipt of government funding where there is a corresponding or reciprocal responsibility to deliver specified outcomes in accordance with agreed arrangements, such as financial transfers, grants, or contracts (ANAO 2012a). This can apply to non-governmental organisations, private 
contractors and sub-contractors, publicly owned companies, as well as national and sub-national governments - depending on the mandate granted to the auditor. The term 'cross-jurisdictional performance audit' was developed by the researcher to use in place of 'follow-the-money' audits in order to emphasise the jurisdictional element involved in this type of application of performance audit.

Though there is little explicit reference in the academic literature to CJPAs in the context of sub-national governments, gray literature indicates they do occur. Pinpointing cases of CJPAs where a national audit agency is accessing jurisdictions already covered by sub-national auditors-general has been difficult, however this process will be reported in later sections of this chapter. When compared to cooperative audits, CJPAs of sub-national governments are another way to address issues shared between levels of government. The main difference is that there is little, if any, formal cooperation with other audit agencies in undertaking audit work in a government jurisdiction outside of its own. However, despite any formal agreements or involvement of a second audit agency in the conduct of CJPAs, there is still space for consultation and sharing of information between the auditors-general and the audit offices, depending upon the willingness of the other office to cooperate.

Examinations of preliminary ANAO documents suggest that CJPAs will involve at least some consultation or contact with the audit agency representing the audited jurisdiction. For example, in a recent presentation, the Commonwealth Auditor-General stated his intent to consider 'the views of the JCPAA and other stakeholders, including those in state and territory jurisdictions' (McPhee 2012 b, p. 5). He also suggested the possibility of 'utilising the expertise of the state and territory Auditors-General and participation in state and territory Parliamentary inquiries' (McPhee 2012b, p. 5).

\section{Summary}

This section provided a review of the literature relating to key areas of performance audit theory and practice considered most relevant to this study. The literature on the origins, development and expansion of performance audit clearly illustrate how the practice developed alongside the reforms of NPM, and that it represented one part of a greater shift in perspective on accountability in the public sector. At the same time, these changes have also impacted the AuditorGeneral's ability to provide such assurance, and therefore constant review of the mandate and governing legislation is necessary to ensure appropriate access is provided.

Due to the network of relationships that an auditor-general is typically subject to, it is not surprising that the practice of performance audit also operates within a system of constraints. The primary stakeholder relationships of the Auditor- 
General can all have an influence on performance audit, and likewise they can themselves be influenced by a performance audit. This network of influences means that changes to any one part of the system are likely to have implications for the other parts.

New trends in performance audit, such as CJPAs or follow-the-money powers, as well as more cooperative approaches amongst audit offices, are on the rise in order to address areas identified as gaps in accountability and oversight and show promising potential for improving performance audit impacts and public administration more broadly.

Informed by the literature review, a conceptual framework is set out in Figure 10 to help guide this study. Drawing on Pollitt et al. (1999) and Van Looke and Put (2011), the framework has been modified to include other potential relationships which may be affected with the addition of CJPAs. The framework depicts the relationships of influence on the performance audit process at the ANAO, as well as the outward influence that performance audits can have on the broader organisational environment. 


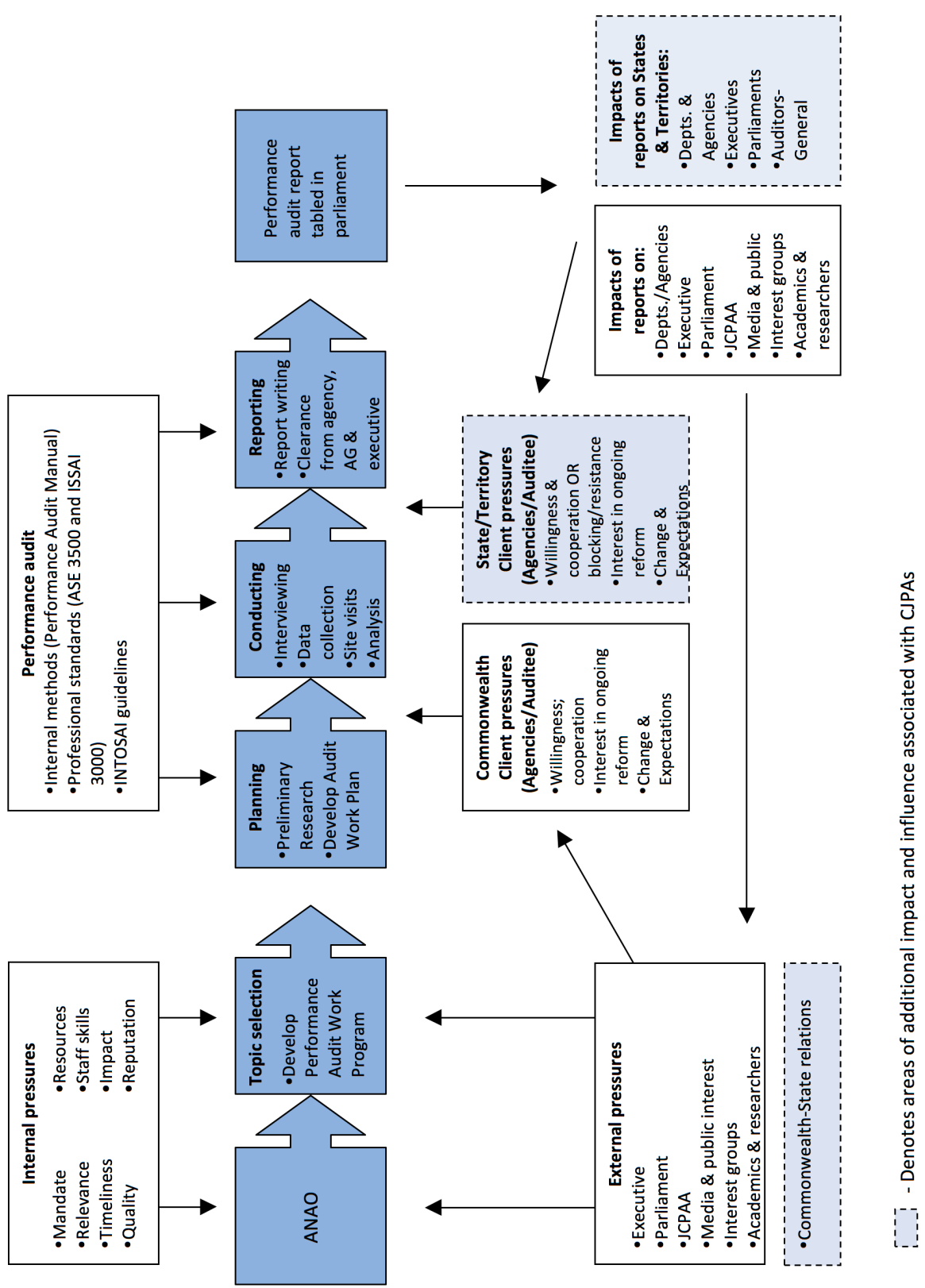

Figure 10: Cross-jurisdictional performance auditing at the ANAO: Process and influences

Source: Adapted from Pollitt et al. 1999, and Van Loocke and Put 2011. 


\section{Methodology}

The research design for this study relied on a qualitative methodology consisting of three discreet approaches including a jurisdictional scan, interviews, and an online survey.

The jurisdictional scan identifies other national audit agencies that have experience in the conduct of CJPAs or cooperative performance audits and to gain insight into how they are applied and how often.

Semi-structured elite interviews were conducted with key stakeholders and selected experts in the field of public sector audit or involvement in the JCPAA Inquiry, including six current and two former auditors-general in Australia, the Chair of the JCPAA, the Committee Secretary of the JCPAA, and two senior audit office personnel (see Appendix 1). The aim of the interviews was to explore Australian perspectives on the new CJPA powers as well the various cooperative performance audit alternatives.

An online survey of national audit agencies was conducted to solicit international perspectives on the advantages and disadvantages of CJPAs and cooperative performance audits. ${ }^{6}$

Data collected from each of the three approaches is analysed together to arrive at a comprehensive and well-balanced assessment of the issues central to this study, and is presented later in this chapter.

\section{International jurisdictional scan}

The jurisdictional scan determines whether other national audit agencies were involved in CJPAs or other cooperative approaches to address interjurisdictional audit issues. The goal is to identify good practices to consider. The literature review establishes working definitions for CJPAs and the three types of cooperative audits, and these definitions are used to analyse the findings from the jurisdictional scan.

6 More detail on interview and survey methodology, including a list of draft interview questions and online survey questions, can be found in the original full-length report (Gerald 2012). 


\section{Canada: Cooperative audits with sub-national audit agencies}

The responsibility for external public audit in Canada rests with the Office of the Auditor-General, while all provincial governments have their own external auditors general. While the Auditor-General of Canada may have some followthe-money powers, communications with office staff have confirmed that CJPAs are not conducted by the federal Office of the Auditor-General in any areas under the exclusive jurisdiction of provincial or municipal governments. Though federal audits of the territories do occur, they are not considered to be CJPAs because the Office of the Auditor-General is actually mandated as the responsible external auditor in for the territories, as they do not have their own auditors general.

Although no instances of joint audits were identified in Canada, 12 instances of concurrent audits occurred (18 including follow-up audits), either between the federal Office of the Auditor-General and provincial audit offices or amongst provincial offices.

\section{United States: CJPAs through a federal lens}

The Government Accountability Office (GAO) is the public sector auditor for the US federal government, while each of the states also has their own independent audit offices. The GAO has a clear mandate to conduct CJPAs of state government administration in cases of federal transfers, but they are not undertaken that often, and typically only in cases where there is a substantial federal involvement (personal communication, GAO, 28 October 2012). When GAO audit staff examine a federally funded program such as education or work training programs, 'it is through the lens that focuses on how those goals may differ from federal goals and how that performance needs to be improved ... from a federal perspective' (personal communication, GAO, 28 October 2012). While the GAO may have a real interest in how states are spending federal funds, it is clear that their assessments are focused on how well federal departments are managing their state-level contractors or agents, and does not extend to include any assessment of state-level performance.

The GAO indicated that direct involvement of state audit offices in CJPAs is rare, and limited to consultation and coordination activities to ensure they are not duplicating audit work (personal communication, GAO, 29 October 2012). A representative explained that the GAO is much larger size and resource capability than most state audit offices, and therefore it makes more sense that CJPAs do not draw on the resources of the state level auditors (personal communication, GAO, 29 October 2012). 
Cooperative audits with the state level audit offices do occur, on occasion, relating to topics that are of mutual concern. The only involvement in an international cooperative performance audit that could be identified was an audit on invasive species undertaken in 2003 in partnership with the Office of the Auditor General in Canada.

\section{United Kingdom: An integrated, joint audit approach to CJPAs}

The external public auditor for the United Kingdom is the Comptroller and Auditor-General, an independent officer of the House of Commons supported by the National Audit Office (NAO). On occasion, the NAO conducts CJPAs of the devolved governments of Northern Ireland, Scotland, and Wales, although each of these also has their own independent auditors general. Since funding transfers from the UK government to the devolved governments are not conditional, these CJPAs are not for the purposes of assessing performance against national objectives (since there are none), and instead are used for the purposes of performance comparison across the four countries of the UK (Paun and Hazell 2008). Typically these CJPAs involve active collaboration with the audit offices of the devolved governments, allowing the NAO to draw on their resources and expertise while at the same time providing them a role in the process.

Occasionally, the NAO undertakes joint audits with the Audit Commission, the external public auditor for local government in England and Wales (personal communication, NAO, 16 October 2012). ${ }^{7}$ In these cases the two agencies come together to examine conditional grants provided from the UK government directly to local governments in England of Wales, which are attached to UK government outcomes. ${ }^{8}$ Similar to their CJPA approach, the NAO draws upon the expertise and local knowledge of the Audit Commission.

The NAO has been involved in cooperative audits in the past, but the only recent one that could be identified was a concurrent audit in 2000, with the Netherlands, Sweden, and England (personal communication, NAO, 16 October 2012). Apart from this example, no other international cooperative audits with the NAO could be located.

7 At the present time, the future of the Audit Commission in England is unclear, following a decision by the UK Department for Communities and Local Government to disband it. For more information please visit: http://www.audit-commission.gov.uk/. Audit oversight for local government in Scotland and Northern Ireland is provided by their national audit offices respectively.

8 For example, in 2005 a joint audit was undertaken in with the Audit Commission entitled, 'Delivery Chain Analysis for Bus Service in England', where a joint audit team comprised of members from both the NAO and the Audit Commission worked together to produce a single joint report. 


\section{Norway: Unrestricted access from a unitary perspective}

The initial review of Norway revealed that it does not operate under a federal system of government, but rather as a multi-tiered government based on a unitary constitution (Boadway and Shah 2007). This means that ultimate control for government functions rests with the central government, and responsibilities can be delegated to lower levels by means of legislation. Norway's national public auditor is known as the Riksrevisjonen, or the Office of the AuditorGeneral of Norway, but it is not responsible for providing oversight to the local governments because they each have their own requirements for an external public audit function. Nevertheless, the Office of the Auditor-General can conduct CJPAs of financial transfers to local governments at their discretion when the funds are tied to specific national policies, and these audits do not have any involvement from the local audit agencies. Provisions for such audits are enshrined in the Office of the Auditor-General's governing legislation, which provides the right to access information and carry out investigations of anyone, 'to whom central government tasks have been delegated or who supply goods or services to the state' (Riksrevisjonen 2011, p. 16).

Cooperative audits in Norway were identified, typically between the Office of the Auditor-General and other Nordic countries, and relating to environmental issues. However, more recently a concurrent audit with Russia relating to the management of fish resources was conducted in 2008.

\section{Switzerland: CJPAs with a role for sub-national cooperation}

The Swiss Federal Audit Office is the independent federal public auditor of Switzerland. The Federal Audit Office's mandate allows for CJPAs to be conducted of the sovereign cantons (state governments), in areas where federal financial aid has been provided. The mandate also recommends that the cantonal level audit offices should be involved in any CJPA, but that such audits are to be led by the Federal Audit Office, and duties can be delegated at their discretion. The Federal Audit Office reports a high degree of cooperation with the canton level audit offices in this regard, which suggests that there might be advantages to working with the sub-national audit offices in the CJPA process in order to share the workload, access their specified knowledge base, and take advantage of their existing relationships with audit subjects. The Swiss case therefore provides a good example of how to integrate sub-national audit agencies into the CJPA process. 
Few cooperative audits were located for the Swiss Federal Audit Office, however one concurrent audit with Hungary was located from 2005 concerning tunnel and bridge infrastructure.

\section{Germany: Cooperation with respect for autonomy}

The federal external public audit function in Germany rests with the Federal Court of Audit, the Bundesrechnungshof, while each of the 16 autonomous Länder (state governments) also have their own independent audit agencies. The Bundesrechnungshof has legislated powers to conduct CJPAs of the Länder governments in cases where they implement parts of the federal budget or have expenses reimbursed from the federal exchequer, if they manage federal funds or assets, or if they receive grants from the federal exchequer' (Bundesrechnungshof 1997, p. 7).

However, since tax revenues are shared in Germany, many programs are funded jointly by the federal and state governments, which result in overlaps in responsibility. In these cases the public auditors at each level of government must cooperate with one another to 'seek harmonization on fundamental issues' (Bundesrechnungshof 2012). This harmonisation is enshrined in the federal audit legislation, which refers specifically to joint audits and clarifies that 'where both the Bundesrechnungshof and a State Court of Audit are responsible for the audit, this should be carried out jointly' (German Federal Budget Code, Part V, Sec. 93, Art. 1).

While the joint approach is enshrined in legislation, the same legislation also states that 'the Bundesrechnungshof may agree to transfer any of its audit functions to the State Courts of Audit', and 'may also agree to take over audit functions from the State Courts of Audit', which provides the federal auditor with the maximum flexibility to address shared issues relating to jointly delivered programs, and adjust the workload to accommodate one another's priorities.

The Bundesrechnungshof has also been involved in cooperative audits with other SAIs, the most recent of which was conducted with the SAIs of Belgium and the Netherlands on intra-community value-added tax fraud.

\section{Austria, South Africa and India: A national approach}

Reviews of Austria, South Africa and India reveal that while their political arrangements as federal systems had much in common with Australia, their public sector audit function did not. All three of these countries have only one national auditor-general responsible for auditing the entire public sector, 
including national and sub-national government departments and agencies. Rather than having independent sub-national level auditors-general, the national audit-offices have regional offices across each country's sub-national districts that specialise in auditing their regional and local affairs. As a result, CJPAs of sub-national jurisdictions in these cases are not possible in the same way as they are in Australia, as they do not have same complicating factors of sub-national sovereignty and sub-national audit jurisdictions.

In terms of cooperative audits, Austria and South Africa have both been involved with cooperative performance audits with other SAIs relating to environmental issues. Most recently Austria has been involved with an audit on climate change with several other European countries (WGEA 2012). Cooperative audits involving India and other SAIs were unable to be located.

\section{Summary}

The jurisdictional scan and resulting cases reveal several important findings. First, the conduct of CJPAs is not entirely uncommon internationally. Second, there is a wide variation in how sub-national audit agencies can be integrated into the CJPA process. Some countries, such as Norway, do not provide any role for sub-national auditors, while others such as Germany actually make cooperation between audit offices mandatory. Switzerland and the US appear to take a more flexible and voluntary approach to sub-national involvement, while retaining the control of the audit. At the extremes, Canada does not conduct any CJPAs of its provinces, while the UK has opted for the most integrated approach of joint audits with the local government Audit Commission, consisting of joint audit teams and a single joint report.

The occurrence of cooperative audits was also found to a varying degree across the jurisdictions examined. Canada is of particular note with respect to frequency of concurrent audits.

\section{Interviews}

This section reviews the findings from interviews conducted with 12 key individuals possessing specialised knowledge about public sector audit in Australia. ${ }^{9}$ For a list of participants see Appendix 1. Responses have been summarised and any direct quotes that have been included are not attributed

9 One interview included two participants - the Commonwealth Auditor-General and the senior ANAO staff member - and their responses have been considered as one, reducing the total number of interviews to 11 . 
due to the small sample size and the high-profile roles of those interviewed. Responses were organised by key themes that emerged following data analysis and only those most relevant to the current study are reported below.

\section{Cross-jurisdictional performance audits}

The majority of participants viewed the new CJPA powers as a valuable addition to the Commonwealth Auditor-General's mandate, however, a few stated that this was so long as these powers were not used to assess the states and territories themselves. Several commented that the mere possession of the new powers gave the Commonwealth Auditor-General more clout, suggesting that their looming threat will be enough to foment changes to both federal and state level management practices. As one participant explained, people have now been 'put on notice' that the federal auditor may come to examine their practices.

Participants highlighted a variety of potential benefits that will flow from the conduct of CJPAs, including the ability to tell the full story about how financial transfers are managed, the ability to provide proper assurance to Parliament, and the opportunity to compare and contrast the delivery approaches of the states and territories. Several also suggested that the new powers would mark the beginning of improved relationships amongst all auditors-general in Australia, both through the increased consultation required for CJPAs and through stimulation of debate about a possible return to exploring cooperative audit approaches.

Most participants viewed follow-the-money powers more generally as an important tool for all auditors-general in Australia, describing them as a way to 'catch up' or 'keep in step' with changes in public management. At the same time, almost half of participants admitted that they felt they were unable to oppose the new powers because they had already advocated for the states and territories to have those same powers, explaining that it might be hypocritical not to support the changes and difficult to argue against the proposal in terms of good public policy and governance.

\section{Cooperative audits}

References to cooperative audit approaches, either in addition to CJPAs, or as an alternative to them, arose frequently in all interviews. More than half of all participants suggested that the Commonwealth Auditor-General should have both approaches at his disposal, representing another tool in the toolkit, to be used depending upon the context and circumstances. 
Despite overwhelming interest in the cooperative audit approach, participants pointed to several barriers that remain before more work can be done in this area, including legislation limitations, priority conflicts, and timing of performance audit cycles. Legislation issues cited by more than half of the participants relate to limitations on information sharing between audit offices. ${ }^{10} \mathrm{~A}$ few participants pointed out that their audit legislation is currently under review to allow for more cooperation, while others suggested that there are already ways to work around these issues. Differing priorities and performance audit cycles were indicated as impediments because, as one participant explained, 'just trying to get agreement, you know, in very good faith, between all the jurisdictions, around a suitable topic, is not easy to do.'

\section{Joint audits}

The joint audit approach was strongly supported by half of participants. One cited it as an 'aspiration', one as the 'preferred approach', while yet another stated that it 'made an enormous amount of sense' for the average citizen, who is not concerned with the jurisdiction of an audit so long as they find out whether there is value being achieved for their tax dollar. Supporters of joint audits identified several advantages to its integrated approach, including the ability to pool resources and leverage expertise using a joint audit team.

Other participants identified barriers to joint audits, including information sharing restrictions, and administrative and personnel issues that could arise when composing an inter-jurisdictional team. Questions about which legislation team members would work under, which set of rules would they be held accountable to, and by whom they would be paid, were all identified. Others downplayed these concerns, explaining that many offices already support secondments, exchange programs and other arrangements, so administratively they would find solutions.

\section{The nature of federal transfers}

The most prominent area of disagreement amongst participants concerned the true meaning of the federal transfers, and how they are or should be perceived in the context of Australian federalism and the current vertical-fiscal imbalance.

10 One participant summarised the issue as follows: 'The ability for audit offices to share information is a good thing from an audit perspective, but it's another thing for governments and parliaments to be comfortable with that, because you need to appreciate that on the one hand, auditors-general have got quite wide powers of access - for instance we have access to Cabinet information, and other information - and so, if you just have sort of a sharing provision ... that suggests an auditor could pass on information about sensitive government matters to one of their colleagues ... and parliaments are sort of saying we need to think very carefully about how any such provisions are framed.' 
On the one extreme, some participants pointed to the states and territories as simply agents of the Commonwealth when in receipt of the federal transfers, rendering them no different from any other contractor, private or otherwise. As one participant put it: 'grants are grants ... I don't think there should be any equivocation about that'. On the other extreme, some participants pointed to the transfers as merely flows of revenue back to the states and territories, which had been collected by the Commonwealth on their behalf. As one explained: 'it's not actually a payment for buying a particular item of activity'. Participants with the latter view seemed to suggest that these monies were somehow different in that once transferred to the states and territories, they became state and territory money and therefore only subject to audit in the state jurisdiction. The remaining participants fell somewhere in the middle, admitting they did not fully understand how the money transformed once it changed hands or how the accountability mechanisms attached to the transfers would change.

\section{Key stakeholder impacts}

The majority of participants referred to the state and territory governments as being 'suspicious' of the new powers, and described them as 'concerned', 'threatened', 'worried', 'apprehensive' or 'uncomfortable' about the prospect of their implementation. While most participants expected this initial resistance to CJPAs by state and territory governments, most believed that it was unlikely they would ever pursue a constitutional challenge over their use. Most participants anticipated the eventual socialisation and acceptance of the new process and that concern would begin to diminish as the ANAO develops its credibility and legitimacy through practice. Relationship management through consultation, education and sharing of information were cited as several participants as the best strategies to minimise negative impacts on the state and territory governments.

An overwhelming majority of participants felt that there was a role for state and territory auditors-general in the conduct of CJPAs, primarily through consultation, information exchange, and the sharing of previous experiences in the subject area, such as background information, previous audit reports or risk analysis that might have already been conducted on that particular agency. However, there were also a few participants who believed that any involvement in CJPAs would simply divert scarce resources away from state and territory auditors-general.

\section{Challenges to CJPA implementation}

The majority of participants identified the same key challenges to the implementation of CJPAs including the ANAO's unfamiliarity with state and 
territory systems and administration; potential relationship issues with their bureaucracies; and potential retaliation from state and territory governments if a CJPA is deemed to be too politically sensitive. One participant explained that 'state government activities are not their bread and butter so they will have difficulty efficiently doing those audits as they gain an understanding of the environment and operating area'.

Similarly, almost half of participants identified building and managing relationships with the state and territory bureaucracies as another major challenge to CJPAs, characterising the potential for turf wars, rivalries, obstruction, push-back, and interference. One participant explained that there will always be a 'political issue around a national office auditing a state agency' that will not easily be accepted by the states and territories without a concentrated communications campaign directed at their departments and agencies.

A few participants also identified resourcing as an issue, explaining that securing resources for a CJPA would be a challenge since state and territory level parliaments would have difficulty understanding why their resources were being diverted towards the conduct of an audit for the Commonwealth.

\section{Details on the CJPA process}

All participants surveyed unanimously agreed that in a CJPA, the state and territory auditees should be extended the same privileges of natural justice as those given to Commonwealth auditees, including copies of draft issues papers, an opportunity to respond to the issues papers, as well as the inclusion of their response (or a summary) in the final report. Participants spoke to these features as important to ensure audit quality and credibility. The majority of participants also indicated that CJPA reports should only be tabled in the Commonwealth Parliament.

More than half of the interview participants indicated that they did not feel it was appropriate for the Commonwealth Auditor-General to make direct recommendations to state and territory entities. However, they did support indirect recommendations so long as they are framed as recommendations to the responsible Commonwealth departments. This distinction, they explained, is because 'the Commonwealth should be accountable for their officials discharging their obligations', and that CJPAs are really meant to be about 'looking at the Commonwealth administration, oversight and monitoring of the states and not necessarily the delivery by the states of the services'. Three participants said it would simply not be possible to hold a state agency to account in the Commonwealth and so there was no point in making a recommendation to them. 
In contrast, a few participants stated that direct recommendations should be made to the state and territory agencies involved in a CJPA. One noted that, "if you see opportunities where they might make improvement, it seems to me that it would be a bit unusual not to', while another suggested they do so only after a couple of years of putting CJPAs into practice.

\section{Summary}

Data collected through the interviews uncovered several important insights. While participants generally viewed the new CJPA powers as a positive addition to the Commonwealth Auditor-General's mandate, some felt that CJPAs should not reach so far as to assess state and territory performance. The conduct of CJPAs is anticipated to impact state and territory stakeholders the most, but also the ANAO as they adjust to the addition of a new audit program. Several challenges to the implementation of CJPAs were highlighted, but none seemed insurmountable by the ANAO so long as they are proactive in their approach. Most participants showed a high degree of interest in pursuing cooperative audits, and although most admit these involve more work, time and resources, it was generally agreed that the benefits of these approaches are worth the effort.

\section{Survey}

Findings from the online survey are summarised into two categories, including those that relate to CJPAs and those that relate to cooperative performance audits. The nine audit agencies that responded to the survey and key information about their performance audit practices are summarised in Table 1.

\section{Cross-jurisdictional performance audits}

Of the nine audit agencies who responded to the survey, all indicated that they have conducted CJPAs of other levels of government, except for Mexico and Ireland. Canada explained that they only do so in the case of their three territory governments because they do not have their own auditors general. Similarly, New Zealand indicated they are the only public sector auditor and therefore are responsible for auditing all public sector entities, including the local authorities. The Netherlands clarified that they do not have an official mandate to access the sub-national departments and agencies, but instead their involvement is voluntary. Overall, the responses suggested that involvement by sub-national audit agencies in the CJPA processes is typically limited, although two agencies did report closer involvement (the UK and Switzerland). 
Several challenges to conducting CJPAs were reported, including difficulties in accessing information, variations in agency capacity and expertise, more time consuming process, and differences in timing and scheduling. However, respondents also identified a range of opportunities associated with CJPAs, including the ability to examine the full picture of national spending, improved audit impacts, the ability to compare performance across multiple jurisdictions, and occasions to improve relationships with other audit agencies.

\section{Cooperative performance audits}

Seven participants indicated they have taken part in some form of cooperative performance audit, with two stating they have experience with all three (UK, The Netherlands), while others (Canada) were involved in only the concurrent variety. Only New Zealand and Mexico stated that they had not been involved in cooperative audits, but that they would like to in the future.

Most participants stated that the biggest challenge to cooperative audits is that the process can take longer and involves a large degree of coordination and consultation between the agencies involved at each of the performance audit phases. However, despite these challenges, respondents identified many opportunities that arise from cooperative audits, again supporting the ability to see the complete picture, improve impacts of the audit, as well as the advantages of pooling knowledge and expertise from two audit agencies.

\section{Summary}

The key results from the online survey have been summarised into Table 1.

Table 1: Online survey summary: International CJPA and cooperative audit practices

\begin{tabular}{|l|l|l|l|l|}
\hline & $\begin{array}{l}\text { CJPA of } \\
\text { other level of } \\
\text { government? }\end{array}$ & $\begin{array}{l}\text { Involvement of audit } \\
\text { agency responsible for that } \\
\text { jurisdiction? }\end{array}$ & $\begin{array}{l}\text { Cooperative } \\
\text { performance } \\
\text { audits? }\end{array}$ & $\begin{array}{l}\text { Which } \\
\text { types? }\end{array}$ \\
\hline New Zealand & Yes & $\begin{array}{l}\text { No, OAGNZ is the only audit } \\
\text { agency (i.e. no local gov. } \\
\text { auditor) }\end{array}$ & No & N/A \\
\hline UK* & Yes & $\begin{array}{l}\text { Yes, through joint working, } \\
\text { combined visits }\end{array}$ & Yes & All three \\
\hline Canada & $\begin{array}{l}\text { Yes, but } \\
\text { territories } \\
\text { only } \\
\text { (NWT,YK, } \\
\text { and NVT) }\end{array}$ & $\begin{array}{l}\text { No, OAG is only audit office, } \\
\text { none in the territories }\end{array}$ & Yes & Concurrent \\
\hline
\end{tabular}


12. Cross-Jurisdictional Performance Audits

\begin{tabular}{|l|l|l|l|l|}
\hline & $\begin{array}{l}\text { CJPA of } \\
\text { other level of } \\
\text { government? }\end{array}$ & $\begin{array}{l}\text { Involvement of audit } \\
\text { agency responsible for that } \\
\text { jurisdiction? }\end{array}$ & $\begin{array}{l}\text { Cooperative } \\
\text { performance } \\
\text { audits? }\end{array}$ & $\begin{array}{l}\text { Which } \\
\text { types? }\end{array}$ \\
\hline $\begin{array}{l}\text { The } \\
\text { Netherlands }\end{array}$ & $\begin{array}{l}\text { Yes, but } \\
\text { cooperation } \\
\text { is voluntary }\end{array}$ & No & Yes & All three \\
\hline US & Yes & $\begin{array}{l}\text { Yes, through information } \\
\text { exchange }\end{array}$ & Yes & $\begin{array}{l}\text { Concurrent } \\
\text { and } \\
\text { coordinated }\end{array}$ \\
\hline Norway & Yes & No & Yes & $\begin{array}{l}\text { Concurrent, } \\
\text { coordinated }\end{array}$ \\
\hline Mexico & No & N/A & No & N/A \\
\hline Ireland & No & N/A & Yes & Coordinated \\
\hline Switzerland & Yes & $\begin{array}{l}\text { Yes, through information } \\
\text { exchange; optional } \\
\text { involvement }\end{array}$ & Yes & $\begin{array}{l}\text { Coordinated } \\
\text { and joint }\end{array}$ \\
\hline
\end{tabular}

*In August 2010, the UK government announced its intention to abolish the Audit Commission, which was the agency responsible for auditing local government spending. As of 24 September 2012, the NAO website reports that the new audit arrangements will see the NAO not auditing the performance of individual local authorities, but producing a number of value for money reports each year on issues affecting the sector. However, it should be noted that the participant responding on behalf of the UK did so relative to past practices.

\section{Discussion}

The purpose of this chapter is to assess the impacts of the addition of CJPA powers to the mandate of the Commonwealth Auditor-General for Australia, which allows for audits to be conducted of states and territories when in receipt of federal transfers with attached Commonwealth objectives or outcomes. The assessment of impacts is conducted with a view to external stakeholders and internal considerations of the performance audit process at the ANAO, as well as consideration of cooperative approaches to performance audit as an alternative or additional approach to the ANAO's overall mix of audit activities.

This section includes a discussion of the implications of the key interview and survey findings in the context of the background, literature review, and jurisdictional scan, and is organised into three main parts: the first part discusses the implications of the findings relating to CJPAs and their impact on the various stakeholders identified throughout this study; the second part discusses the implications of key findings associated with cooperative audits; the third part summarises the overall discussion. 


\section{Cross-jurisdictional performance audits}

Overall, the interview data was consistent with the information presented in the background section with respect to the anticipated concerns about the introduction of CJPA powers. Participants tended to view the addition of CJPA powers as a valuable tool for the Commonwealth Auditor-General because it will allow him to conduct end-to-end performance audits of federal transfers to states and territories, and provide Parliament with the full story in their final report. According to the interview data, the impacts of this power will also have effects further afield, since the mere possession of CJPA access effectively puts the states and territories on notice for a possible audit from the Commonwealth auditor, and this might encourage state and territory agencies to tighten up some of their practices in advance of any announced audits, in the same way that this can occur with federal auditees.

The interview data has also made it clear that there are many differences in opinion and understanding of the nature of the federal transfers that take place under SPPs and NPPs and that these underlying differences may be at the root of the disagreements over the conduct of CJPAs. For example, several participants referred to the transfers as being a payment for a service, equivalent to the exchange that takes place with a contractor. At the same time, several other participants indicated that they perceived the transfers as a redistribution of tax revenue collected by the Commonwealth on behalf of the states and territories, and that these transfers are not actually a payment for a service, but instead merely a flow of revenue. So clearly there remains some confusion as to the status of the federal financial transfers and the interview data seems to support this notion that one's perspective on the value of CJPAs is dependent upon what jurisdiction you represent. It is in this vein that it appears easier to rationalise the practice of CJPAs of sub-national governments in countries such as Norway, the Netherlands, and the UK, since they take place within unitary systems where sub-national governments really are more like service delivery conduits for national policy as opposed to the independent, autonomous units that are present in federations such as Australia.

Interview findings were also consistent with the literature on the issue of 'erosion of mandate' of auditors-general, which refers to the loss or impairment of an auditor-general's ability to assess or provide assurance of public sector performance in cases where services have been contracted out of the government sector and into either private or non-profit organisations. More than half of the interview participants indicated that follow-the-money powers in general were critical to ensuring auditors-general can continue to assess performance in these cases, because ultimately governments are still responsible for the provision of public services, despite their being outsourced. However, the conflation of the various types of cross-jurisdictional access into one access power - the 
ability to audit any Commonwealth partner — also made it difficult for many of the auditors-general to oppose the amendments, particularly when they had advocated for these powers in their own mandates. The interview data shows that although most participants supported CJPAs or follow-the-money audits of third parties, including local governments, NGOs and private businesses, several had indicated that they were less certain about CJPAs of states and territories, due to the impacts this might have on their autonomy.

Finally, more than half of those interviewed felt that that while the Commonwealth Auditor-General should have sufficient oversight powers, external audits exist to provide oversight; the intent is not to scrutinise all Commonwealth government operations. Strong internal assurance and accountability mechanisms must be built in to all government operations and managed from the inside, with the external auditor reviewing them from time to time to assess if they are in need of improvement. Most interview participants suggested that the overall accountability framework of the Commonwealth could be best strengthened through the COAG forum, particularly the COAG Reform Council and the National Partnership Agreements. Improving the clarity and roles and responsibilities in these agreements could help bring about better value for money spending and ultimately improved state and territory outcomes.

\section{Impacts of CJPAs on external stakeholders}

The process of performance audit was identified in the literature as being both influenced by, and having an influence on the various stakeholder relationships of the Auditor-General (Pollitt et al. 1999; Lonsdale 2008; Lonsdale et al. 2011). The importance of these relationships was generally supported in the interview data, which suggested that a change in the Auditor-General's mandate, such as the addition of the CJPA power, will have flow-on effects for a variety of external stakeholders, particularly state and territory auditors-general, state and territory governments, and state and territory auditees - each of which is discussed below. Regular stakeholders of the Commonwealth Auditor-General will be impacted to a lesser extent, and are discussed all together in one final paragraph.

One of the most impacted stakeholder groups discussed in the interviews is that of the state and territory auditors-general. For the most part, impacts were considered to be positive, in that CJPAs could promote partnerships amongst auditors-general through added consultation and information sharing, placing the state and territory auditors-general in a supportive role particularly at the front end of the audit planning process. Likewise, several interview participants suggested that CJPAs are likely to act as a catalyst to promote a renewed interest in cooperative approaches to performance audit, ultimately impacting the 
topic selection activities of all audit offices. There were also concerns about diverting state and territory resources to consult and provide information to the Commonwealth Auditor-General. Whether this would divert more priorities than requests from an MP or JCPAA to investigate a particular matter is an open question.

A second group of impacted stakeholders are the state and territory executive coordinators and central agencies. Interview participants generally felt that the reaction of the state and territory governments to the CJPA powers was not positive, and that they felt threatened, worried or apprehensive about the prospects. Not surprisingly, the state and territory governments have perceived this process as an infringement on their constitutional rights as sovereign and autonomous political units. On the other hand, as one interview participant pointed out, this type of vocal reaction is actually business as usual when it comes to Commonwealth-state relations, and perhaps this sentiment should not be interpreted as seriously as it was earlier in the process. In fact, most interview participants indicated that that they did not expect anything to come of the threats of constitutional challenges - unless, as two participants indicated, the topic was politically sensitive enough. Once CJPAs begin to occur, so long as they are not overly contentious, they will gradually begin to build their credibility with the states and territories, and potentially begin to add value through positive improvements. In the meantime, these sentiments will remain at the government level and could have flow-on effects to the departments and agencies that will eventually become the subjects of CJPAs. Interview data indicates that the extent of these effects can be best mitigated through direct consultation, education and information sharing with the state and territory governments.

A third stakeholder group impacted by CJPAs is the state and territory auditees. The introduction of CJPAs at the Commonwealth level will add another layer of audit to the state and territory bureaucracies, which will likely be greeted with similar sentiment to that of the state and territory governments as described in the previous paragraph. Although the impacts on this relationship were not discussed in detail in the interviews, it is easy to extrapolate from the literature on the auditor-auditee relationship to anticipate some of the impacts on this group. If we consider Funnell and Wade's (2012) study on the auditor-auditee relationship at the ANAO, characterised by animosity, it would be expected that the auditor-auditee relationship between the Commonwealth auditors and state auditees to be potentially worse. Several authors (Lonsdale et al. 2011; Put and Turksema 2011) point to the need for performance audits to be seen to add value to the auditees, and therefore the ANAO must make sure their product is of high quality in order to justify the effort. 
The remaining stakeholders identified earlier in this chapter will also be impacted by the addition of CJPAs to the Commonwealth Auditor-General's mandate, however the findings from the various methods in this study suggest that they will be to a much lesser extent than the previous three groups identified at the state level. At the Commonwealth level, Parliament and the JCPAA will be impacted positively due to the increased confidence that CJPA access will bring through improving their understanding of how Commonwealth funding is being spent under NPPs and SPPs. Commonwealth auditees might be positively impacted during a CJPA if the additional state and territory information helps to better explain their actions or the quality of information they were given by the states and territories. Central agencies and the executive government at the Commonwealth level do not appear to be majorly impacted by these changes, which is of little surprise considering the endorsement of the amendments by the executive following the JCPAA's recommendations. The media, the public, academics, and professional associations will be impacted by a CJPA no more than by the tabling of a standard performance audit, although in the early days of the launch of CJPAs, the new access provisions might become newsworthy.

\section{Internal stakeholders}

As mentioned above, a change in mandate, such as the addition of CJPA powers, can have flow-on effects for an audit agency's internal process of performance audit, similar to those conceptualised in the literature by Pollitt et al. (1999) and Van Loocke and Put (2011). The findings from the interviews and the survey are generally consistent with this notion, and when applied to the ANAO it is clear that the addition of cross-jurisdictional powers has the potential to impact a range of performance audit activities, from planning through the conducting and reporting phases, and additional considerations will need to be made at each phase in the CJPA process.

During the pre-planning phase, it is clear from the interview data that the ANAO ought to begin with CJPA topics that are not too politically sensitive for state and territory governments, in order to allow time to build up the credibility and legitimacy of the process. Some low-risk and positive outcome audits that have little implications for the state and territory level bureaucracies could be a good place to start. A concentrated communications and education campaign from the ANAO about CJPAs was also indicated as essential to reducing the resistance of the state and territory governments. Once the planning phase has begun, the audit team will need to allot additional time to collect background information and to learn about state specific legislation, policies, rules and regulations. Auditors may also want to consult with the state and territory Auditors-General 
about their knowledge and experience about the audit topic or if they have previously conducted audits in this area, although some interview participants indicated there might be varying degrees of cooperation from auditors-general.

In the conducting phase, unfamiliarity is once again the biggest consideration for the audit team. They will be accessing new premises, working with new auditees, and learning about new systems. This may take additional time and auditors could be faced with resistance or less cooperative staff. On the other hand, if this is done well, the ANAO auditors may face less resistance and animosity on the part of the state territory agencies by demonstrating that they are across the issues and have a sound understanding of the state and territory level processes. Additional time considerations might be necessary during the development of issues papers, as all interview participants indicated the necessity of providing the state and territory agencies with issues papers and opportunity to comment. The consultation and negotiation period that follows might take more time, especially if findings are less than desirable.

In the reporting phase, auditors will have to consider very carefully whether or not they will make recommendations to the state and territory agencies. More than half of the interview participants felt that direct recommendations to states and territories should not be made, and that instead they should be directed at the responsible Commonwealth department or agency. On the other hand, some interview participants felt that if there were areas identified for improvement, that recommendations are a natural part of the performance audit process, so clearly there remains some disagreement as to the best approach to recommendations in CJPAs.

Finally, the tabling of reports also needs to be considered. Although most interview participants felt that the reports should only be tabled in the Commonwealth Parliament, several others indicated they believed there should be some mechanism or forum for the states and territories to discuss the findings of the report relevant to them. It would seem that the ANAO should consider producing alternate forms of the report for the state and territory auditees, or otherwise make them available upon request. 
12. Cross-Jurisdictional Performance Audits

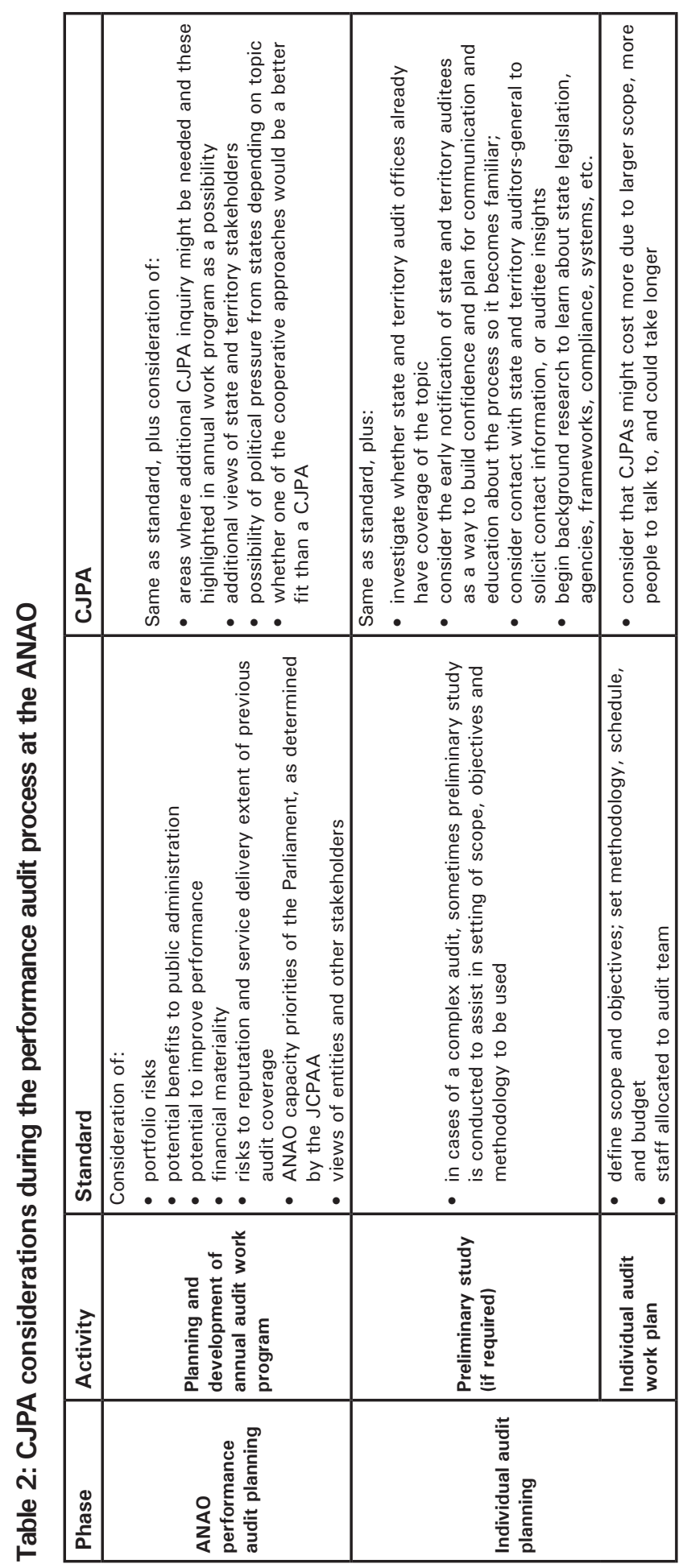




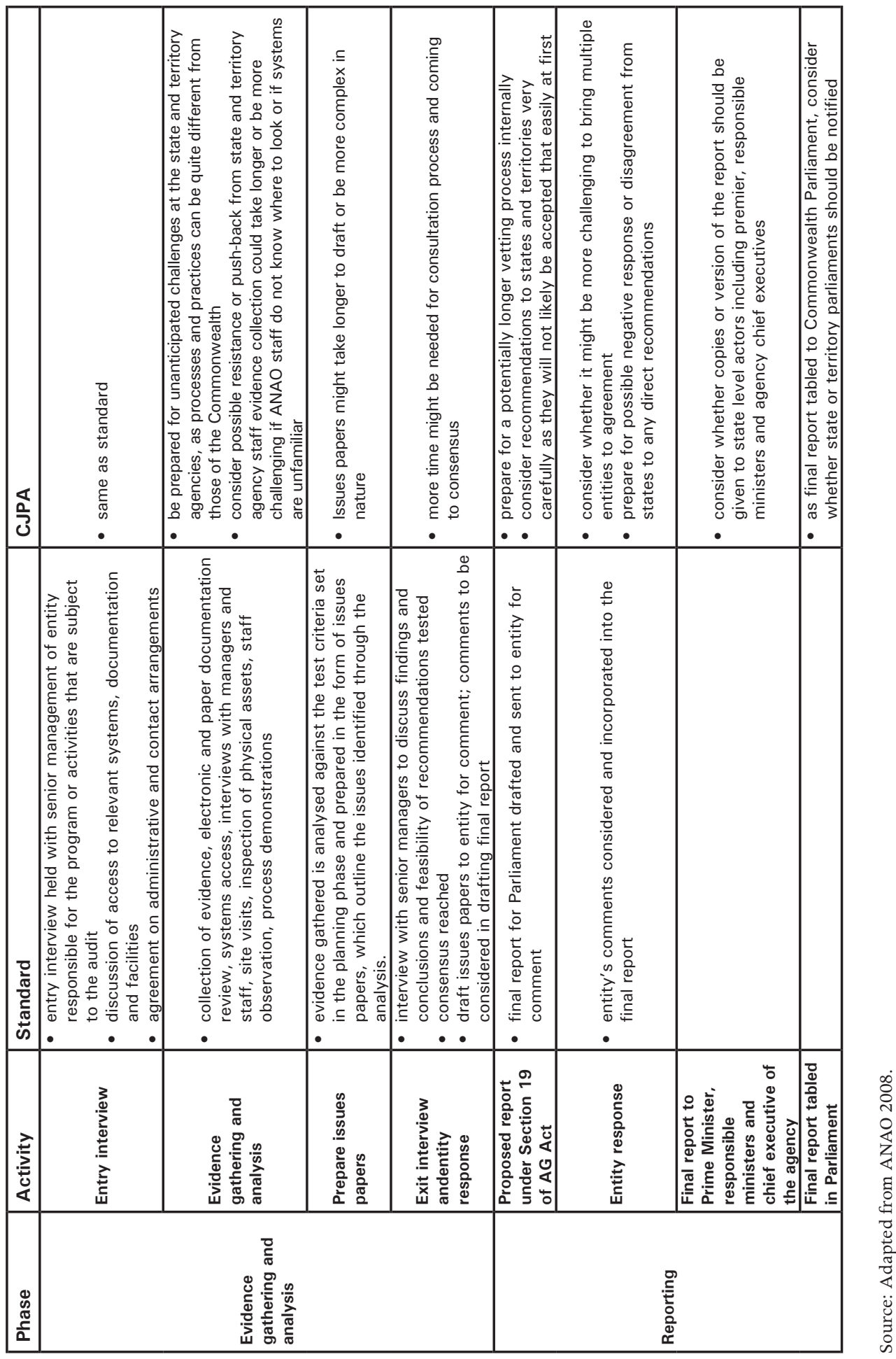


Overall, the conduct of a CJPA will require a variety of additional considerations to be taken at each step in the performance audit process, and these are summarised and presented in Table 2. It is anticipated that many of these considerations will diminish over time, as the practice of CJPAs becomes more frequent and better understood.

\section{Cooperative approaches}

The benefits of engaging in cooperative approaches to performance audit were generally supported across all methods including the literature review, jurisdictional scan, interviews, and online survey. Much of the professional literature and guidance from INTOSAI indicated that many SAIs have had success with cooperative approaches to environmental audit, and that the practice has increased substantially in recent years (WGEA 2012). The jurisdictional scan and survey data also indicated that the cooperative approach has spread beyond environmental audits and is being used by many SAIs to tackle a range of problems shared by multiple jurisdictions, including those shared between national and sub-national governments. The interview data was generally supportive of the benefits that a cooperative approach could offer to Australia and demonstrated a desire to further pursue these approaches more often. However, it was also clear that some hesitation remains as to the efficacy and practical realities that may arise in the development of such an approach.

In the most general sense, the barriers to pursuing cooperative audits in Australia relate primarily to priorities, resources, secrecy provisions, and timing, and are consistent with those and others identified in the literature and the survey. The latter two - secrecy provisions and timing - appear to be the easiest to resolve through legislation amendments and the demonstration of flexibility by audit agencies with respect to their timing and tabling programs (see Appendix 2 for current information-sharing capabilities of Australian auditors-general). The sharing of Cabinet-in-confidence information and other sensitive information amongst auditors has also been identified as a real concern by parliaments, however others believe that internal policies can be developed to ensure that these items are not shared by auditors between jurisdictions in cases where they are not deemed necessary. Auditors already operate with high-level security clearances and are familiar with their responsibilities relevant to the protection of sensitive information, so it seems that this barrier can be overcome.

With respect to differing priorities, coming to an agreement on an audit topic may well face resistance due to the various demands of the parliaments in each participating jurisdiction. On the other hand, as independent officers of the Parliament, it is also an auditor-general's responsibility to identify areas of priority, and if there are gaps, black spots or other areas they believe are worthy 
of audit, then they are within their rights to pursue such topics. In the context of federal transfers to states and territories, often they are supplemented by state and territory funds, potentially producing programs of interest to both the Commonwealth and State or Territory auditors-general, so surely it would not be difficult to identify areas of mutual interest. Resourcing these areas of mutual interest, however, might be difficult due to the variations in resource capacity, particularly with performance audit budgets, so a policy of voluntary participation might be optimal. For example, as a larger organisation with a substantial performance audit budget, the Commonwealth Auditor-General may have substantially more resources and flexibility at his disposal as compared to some state and territory audit offices that conduct only a handful of performance audits annually.

Despite these concerns with the difficulties associated with cooperative audits, the cooperative approach was still identified in the interview data as the preferred approach to the CJPA or 'go-it-alone' approach that has been adopted by some national audit agencies to assess the spending of national financial transfers to sub-national levels of government. In particular, the coordinated and joint audit approaches seemed able to remedy one of the most commonly reported difficulties of the CJPA approach - that being the unfamiliarity of the national audit agency with the business and processes of the sub-national departments and agencies. The coordinated and joint approaches also allow for the legitimisation of the process by providing a role for the sub-national audit agencies. These agencies act as experts in the sub-national government field, and allow for more information exchange, as well as the division of labor to maximise areas of expertise.

\section{Concurrent}

The specific application of the concurrent approach was identified in the literature (INTOSAI 1998, 2004) and survey data as being the easiest of the cooperative approaches to performance audit due to the minimal extent of integration required by participating audit agencies. Apart from topic selection and a rough timeline, concurrent audits allow for greater coverage of an issue area without much deviation from an audit agency's typical performance audit process and cycle. The jurisdictional scan revealed Canada as a frequent practitioner of concurrent audits and a proponent of the approach as an opportunity for the national audit office to share their capacity with the provincial audit offices. In Australia, concurrent audits were identified as a good starting point for a more cooperative approach to be taken between audit agencies, however many of the interview participants identified a preference for a more integrated approach, 
one resembling a coordinated or joint audit. Both interview and survey data were consistent with the literature regarding the limitations of the concurrent approach — that being their overall limited impact.

\section{Joint}

The data from the interviews and the survey were also consistent with the literature on the joint approach, suggesting the overall desirability of joint audits over all other approaches, but at the same time acknowledging the various barriers that some agencies might face in realising this approach - reiterating why they are quite rare in practice. In Australia, interview participants identified barriers such as confidentiality and secrecy provisions in the governing legislation of auditors-general as a barrier to joint audits, along with administrative concerns, such as how to integrate employees from two different jurisdictions under one set of rules and regulations, salary, and methodological approaches to performance audit. Nevertheless, these concerns do not appear to be insurmountable - as legislation can be amended and policies and regulations can be altered - particularly in light of joint audits having occurred elsewhere in the world (UK, Germany), pointing to opportunities for guidance or advice to be obtained through contact with international partners. Furthermore, it appears that joint audits are perceived to be the most credible approach to auditing federal transfers to states and territories in Australia, as they legitimise any recommendations arising from the audit due to the direct involvement of the state and territory audit offices - neutralising any cries of infringement on sovereignty or constitutional rights. Finally, joint audits were indicated in the literature and the interviews as being perceived as the most comprehensive approach to shared issues due to the maximised integration of the two jurisdictions via a single audit team, and despite their greater time commitments, they ultimately hold the most potential to produce a high quality audit with the greatest impact.

\section{Coordinated}

The coordinated approach was portrayed in the literature as a good middle path approach between concurrent and joint audits, one that is flexible enough to be adjusted to suit the desires of the participating audit agencies (INTOSAI $1998,2004)$. The survey data also seemed to support this and was indicated as a practice undertaken by several of the surveyed audit agencies (UK, Netherlands, US, Ireland, Norway, and Switzerland). Naturally, the coordinated approach will take more time overall, as it requires frequent consultation and coordination by all participating audit agencies throughout each phase of the audit, and consensus has to be reached on a variety of significant decisions, including choosing the scope, methods, timelines and reporting style. The tradeoffs, however, were indicated in the literature and the survey data, pointing to a 
better quality audit product with greater impact than a concurrent audit, as well as much closer relations between audit offices and greater opportunities to collaborate and improve relationships. An overall summary of the advantages and disadvantages of all approaches to inter-jurisdictional performance audit are presented in Table 3.

\section{Summary}

This section presented a discussion of the main findings from the literature review, jurisdictional scan, interviews and online survey within the broader Australian context. Overall, it is clear that CJPAs are viewed as a positive addition to the Auditor-General's mandate, as they will finally enable the full story through end-to-end performance audits of Commonwealth financial transfers to states and territories, and will provide the Commonwealth Parliament with a renewed sense of confidence in the accountability process. An impacts assessment was also presented indicating that the majority of impacts from this new power will be felt at the state and territory levels as well as internally at the ANAO. Finally, a discussion of the advantages and disadvantages of the crossjurisdictional and cooperative approaches to performance audit was presented, which concluded that that the choice of audit type is ultimately contingent upon audit circumstances.

The discussion section also revealed additional insights into the original conceptual framework presented earlier, particularly with respect to the more specific challenges the ANAO might face as it begins to fold in this new set of powers to its current mandate, and how these juxtapose themselves with the alternate approaches (namely cooperative audits), which appear to have widespread interest. With these new considerations in mind, an overlay to the conceptual framework has been developed to outline the more detailed decisions that the ANAO must make when considering a CJPA moving forward (see Figure 11).

Taken together, the findings suggest that there are several challenges to the unilateral introduction to CJPAs, particularly in first one or two years, that could be ameliorated by the involvement of the state and territory auditors to some extent, possibly through staff exchanges or secondments, to aid the ANAO in building their capacity and experience at the state and territory level. The widely supported cooperative approaches, while popular, do continue to retain barriers to their use that will require time, resources and legislation amendments prior to their use. However, cooperative audits do appear to be an optimal approach to be pursued for use in the medium to long term.

Options and recommendations for the Commonwealth Auditor-General and the ANAO are presented in the following section. 


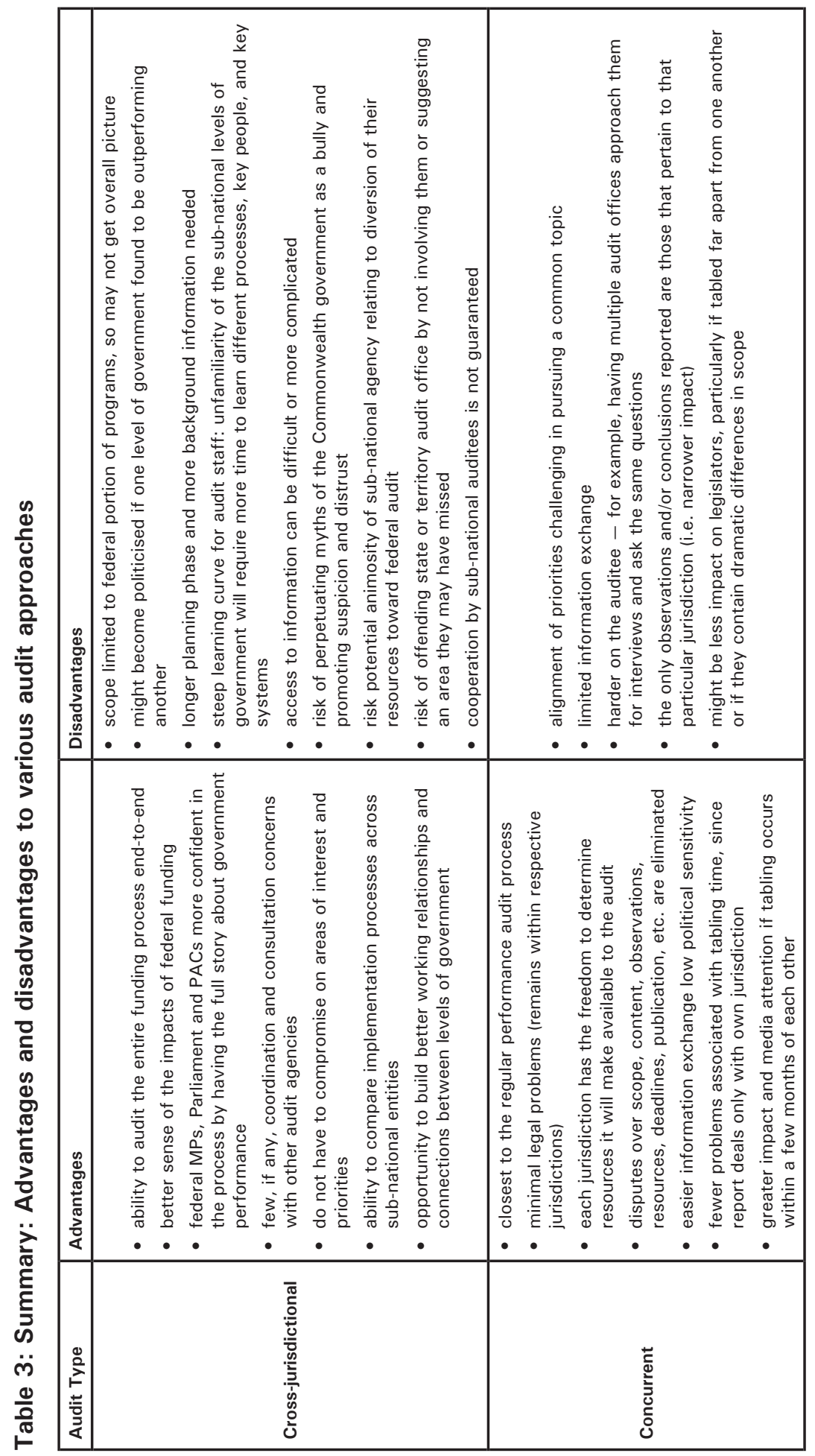




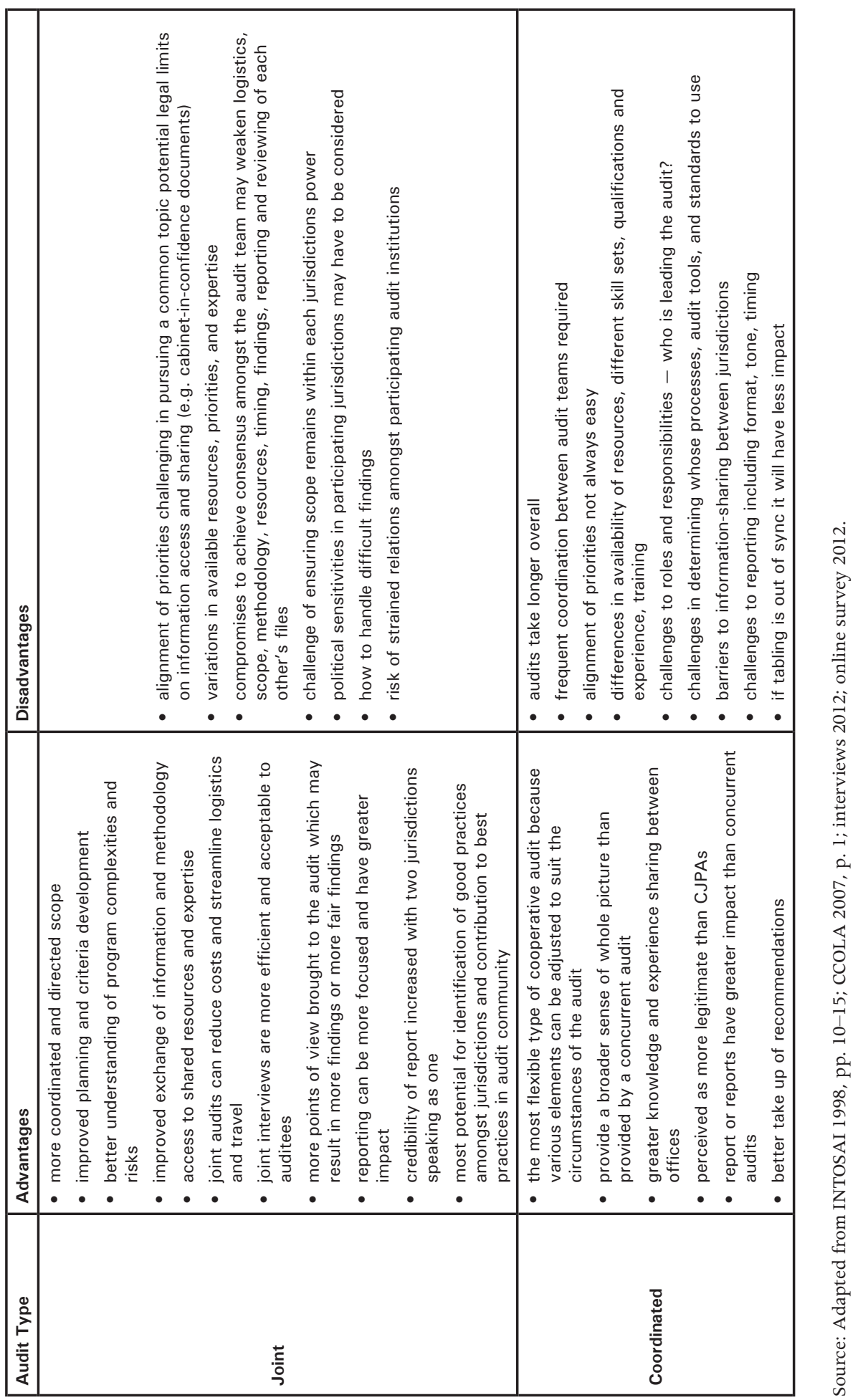


12. Cross-Jurisdictional Performance Audits

\section{|inilipit}
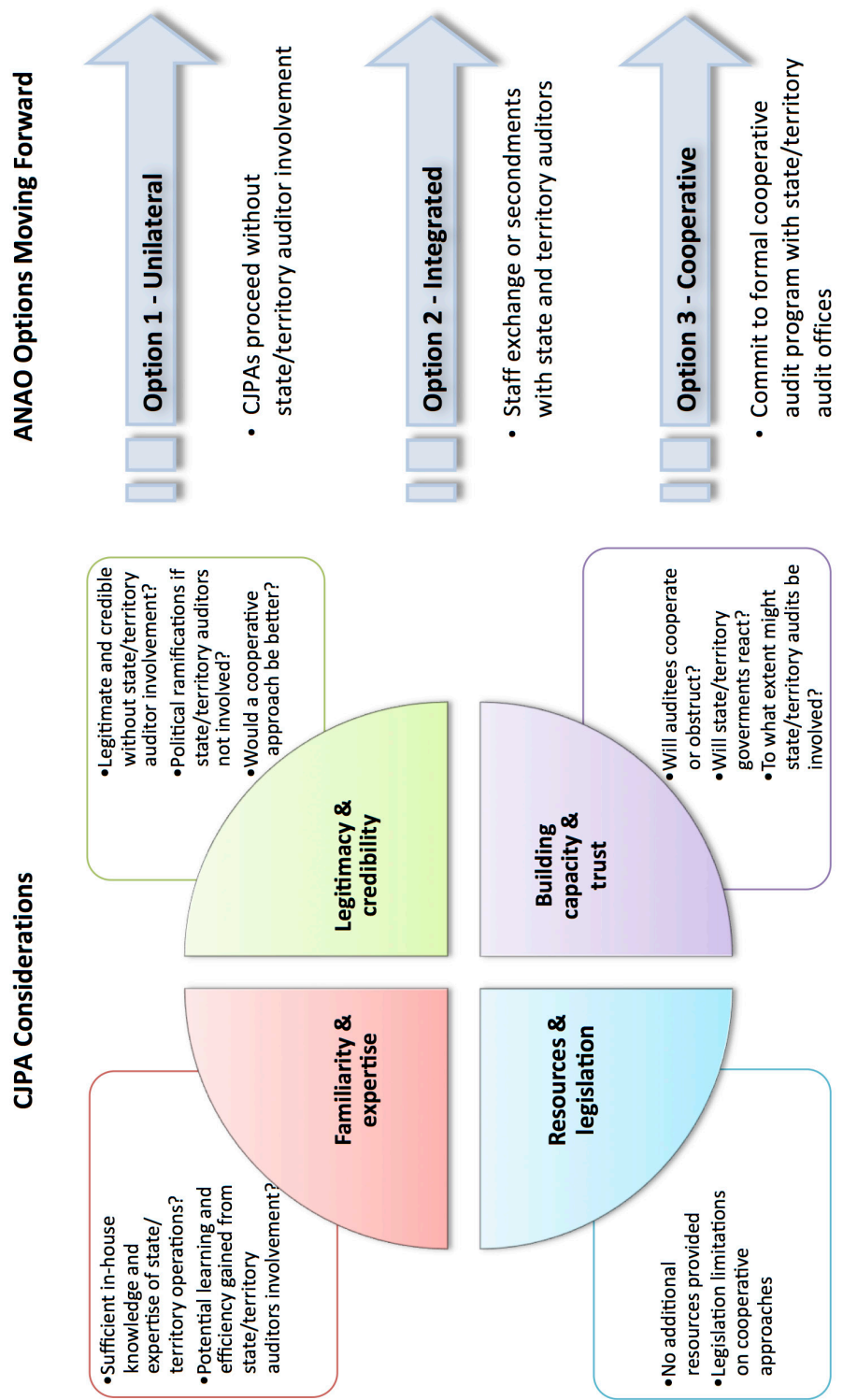

Figure 11: Framework overlay: Considerations from findings for options analysis 


\section{Options, recommendations and implementation}

This section explores the researcher's recommendations to the Commonwealth Auditor-General and the ANAO as they begin to move forward with their new program to conduct CJPAs of state and territories when in receipt of Commonwealth funds for a specific Commonwealth purpose. The recommendations are presented in the form of three options and have been carefully considered in light of the findings from this research, as well as the current realities of resource and legislation limitations. A summary of the option considerations is presented in Figure 12. The options are presented in order of less to more program development and integration with the state and territory auditors-general.

Option 1 - Unilateral: Proceed with a small CJPA program integrated into the annual performance audit program

Commitment to the status quo would see the ANAO proceed as close to normal as possible when beginning to conduct of CJPAs unilaterally, working in a handful of unique CJPAs to their overall performance audit program. For example, out of approximately 55 performance audits per year, three of these could be identified as having cross-jurisdictional components. This would require no additional resources, and no additional staff, as the new CJPAs would simply take the place of previously allocated standard performance audits.

Minimal engagement with stakeholders would take place such as courtesy notifications to the auditors-general of the relevant jurisdictions when a CJPA is about to begin. Contact with premiers or chief ministers could also be made, while contact with state and territory level auditees would be as normal, through designation letters at the beginning of an audit. As shown in the literature review and interview findings, the advantage of a CJPA is that few if any coordination and consultation commitments are required with key stakeholders beyond the initial notifications of the audit. This frees up the ANAO to pursue audits of their choice and on the timelines of their choice.

Topic selection would have to be carefully considered. Topics of low sensitivity to the state and territory governments could be prioritised for the early years and, as confidence is built by the auditees over time, the program could begin to include higher risk audits. There is also the possibility that the pre-planning work could take some additional time for the audit team members to familiarise themselves with the state and territory jurisdiction, so the Annual Audit Work Plan should account for the potentially longer performance audit process.

Overall, this is a realistic option for the ANAO to move forward, because it will require minimal cost and resources by the ANAO and the legislation is 
already in place to conduct such audits. This approach also allows the ANAO to retain control over the audit and guide it through the audit process according to their own criteria, scope, methods, reporting and timelines - with no compromises. The disadvantages of this approach are that the risks associated with the ANAO auditors not attaining a sufficient understanding of the state and territory systems, and producing a poor audit or otherwise difficult debates during the issues paper and recommendation phases. Likewise, if the ANAO ends up with a CJPA audit request from the JCPAA or responsible minister that is of high political sensitivity, they may find themselves insufficiently prepared and facing push-back from the states, making for a difficult and lower quality audit if accurate information is not obtained. If a poor audit is tabled, this could further undermine the credibility of the ANAO and their audit reports.

\section{Option 2 - Integrated: Development of a formal CJPA program that} is committed to the direct involvement of the state and territory audit staff through staff exchange or secondments to the ANAO

The integrated approach would see the ANAO pursue an approach similar to Option 1, but with a more significant commitment to involving state and territory audit staff in the process through audit-specific secondments or direct staff exchange. The knowledge and expertise gained through involvement of the state and territory auditors will help ensure that the new CJPA audits are conducted smoothly. Issues of information sharing are also circumscribed because seconded staff will be subsumed under federal legislation, and governed as federal public service employees. For example, if the ANAO wants to do a CJPA in the area of education, then they could liaise with the state or territory office involve and see if there are any staff available to come to the ANAO that usually work in the state level education portfolio.

To do this, the Auditor-General could begin to liaise with state and territory level auditors-general, and draw up a memorandum of understanding. This will secure in principle commitment from the state and territory audit offices as to their willingness to be involved when they are able. Since this study has shown that the majority of auditors-general in Australia believed there was a role for them in the ANAO's conduct of CJPAs, securing their involvement in some way should not be too difficult. Where possible, the ANAO should pursue direct staff exchanges in order to replenish any staff members drawn on the state or territory level. If this is not possible and a secondment is pursued, then the ANAO will need additional resources to compensate the seconded staff, as well as the state or territory audit agency for their loss in capacity. Alternately, the ANAO could fund these secondments out of already existing secondment budgets, relieving the need for additional resources other than state compensation. The ANAO should develop a compensation plan to address the issue of capacity loss at the state level. 
There are several advantages and disadvantages to this option. On the one hand, commitment to an integrated approach will allow the Auditor-General to capitalise on the knowledge and expertise of the state and territory auditors - one of the biggest challenges to implementation identified in this study and minimise resistance on the part of state and territory governments through improved legitimacy. In cases where involvement by state or territory audit staff can be secured, the resulting impacts are likely to be more comprehensive, have more impact and be perceived as more credible - ultimately increasing the uptake of recommendations and improving public management practices.

Furthermore, the direct secondment of staff helps the ANAO retain control over the audit, and avoid all the coordination and alignment difficulties that are associated with more cooperative approaches. There will also be benefits to the state and territory level staff, who will return to their offices with additional insight and learning about the practices of performance audit at the Commonwealth level. This has the potential for flow-on effects in the future if a cooperative audit program is pursued at a later date. On the other hand, it might be difficult to secure resources from some of the smaller audit offices or those that have small performance audit programs and it might be difficult to justify the loss of two staff members to an ANAO audit that is not a state or territory priority, despite the learning opportunities available for the state and territory auditors. Financial compensation from the ANAO, however, could ameliorate this problem by allowing state and territory audit offices to retain additional staff.

\section{Option 3 - Cooperative: Commit to the development of a formal cooperative audit program, to be pursued alongside the CJPA program}

The cooperative approach would see the Auditor-General proceed in a similar way as presented in Option 1, but with a formal commitment to pursuing a program of cooperative audits. Since there still remain some legislative barriers to cooperative audits, the Auditor-General could pursue an amendment to the Auditor-General Act 1997, to allow for the ability to share information with other audit agencies within Australia. This would require prior consultation and bargaining with Parliament, followed by a request to the JCPAA. The AuditorGeneral should also advocate for the state and territory audit offices to pursue similar changes to their legislation.

Through the Australasian Council of Auditors-General forum, the Commonwealth Auditor-General could lead the way on the development of a formal cooperative audit program that would involve the movement towards coordinated and joint approaches to audits that relate to the federal financial transfers. Once a list 
of topics has been identified, joint working groups composed of performance auditors from participating jurisdictions could begin to meet regularly and discuss options moving forward.

There are various costs associated with this option and significant investment of time and resources required. The ANAO will need to request funding from the JCPAA and receive approval. In the pre-development stages, ANAO staff will be required to meet with state and territory staff to work out guidelines for the cooperative audit program that are satisfying to all parties. Once the guidelines are set, the focus will shift to topic selection and participation. A forward plan should be developed to identify topics and participating jurisdictions.

There are several advantages and disadvantages to this option. Through formal cooperation, it will allow better audit coverage of the service delivery, particularly in cases where federal money is combined with state or territory funding - an area where CJPAs do not have coverage as it is only capable of auditing the spending of federal funds. The interviews conducted in this study indicate significant support for the cooperative approach and a preference for it over the CJPA approach, in part because the cooperative approach will have more meaning for the states and territories, and will be of more interest to their parliaments. On the other hand, it is clear that cooperative audits are timeconsuming and will cost more than standard audits, and they require a high degree of coordination and consultation between offices.

\section{Recommended option}

Option 2 is recommended for the ANAO as it begins to move ahead with its CJPA program. Option 2 incorporates all the basic considerations contained in Option 1, with the additional links to the state and territory audit office through a formal secondment program, but does not go so far as requiring the significant time and resource investments that come with a formal cooperative audit program. Bringing in staff from the state and territory agencies will improve the knowledge base of the ANAO in the early days, and mitigate many of the risks associated with entering new audit terrain at the state and territory level. In addition, involvement of the state and territory auditors will improve uptake of the recommendations and improve audit legitimacy.

While this approach appears to be the most realistic at the present time, it does not preclude the eventual development of a cooperative audit program, which has clearly garnered significant support and offers additional incentives that may not be captured in the secondment approach alone. The recommended approach should be considered the best course of action in the early days, but with an eye towards the future development of a cooperative audit program following necessary legislation amendments and budget increases. 


\section{Option 1 - Unilateral}

- CJPAs proceed without state/territory auditor involvement

- no additional resources or legislation amendments required

- lack of specific knowledge and expertise;

- risks of push-back by auditees

- reputation risks if they get it wrong

- legitimacy risks if direct recommendations to state/territory agencies made

\section{Option 2 - Integrated}

- staff exchange or secondments with state and territory auditors

- capitalize on knowledge and expertise of state/territory staff

- boost legitimacy, credibility; reduce resistance from state/territory auditees

- minimal additional resources

- optimal in the early 1-2 years, as CJPAs are unfamiliar

\section{Option 3 - Cooperative}

- commit to formal cooperative audit program with state/territory audit offices

-additional time and resources required

- approval from JCPAA required

- improved audit outcomes

- opportunities to build capacity, relationships and share knowledge

- cooperative approach widely supported

-optimal in the long-term 5-10 years out

\section{Figure 12: Options summary: Strengths and limitations}

Source: Author's research.

\section{Implementation}

Discussed below is a brief implementation strategy for Option 2, including key components to be addressed before the ANAO moves forward with CJPAs. 
The first step will be for the ANAO to begin liaising with the state and territory audit offices and work towards the development of a memorandum of understanding relating to secondments and staff exchanges for the purposes of CJPAs. This will help the ANAO determine which of the agencies would have immediate capacity and which might be more limited. It could also be used to clarify some of the terms and conditions of the secondments or exchanges including agency preferences, however individual employment contracts can also be used as in regular secondment and exchange situations.

The next step will be to develop a compensation plan to be used when secondments are used instead of direct staff exchange. This plan will outline how state and territory agencies would be compensated in the event that a secondment takes place and will include detailed financial information to allow the ANAO to best estimate costs when beginning to pursue a secondment.

The current secondment policy and budget should be reviewed immediately in order to determine how much flexibility exists within the current budget for additional secondments, as well as earmarking potential CJPA secondments for the upcoming year. A review of previous years' annual reports reveals that secondments can fluctuate from year to year, which suggests there is some flexibility in the budget.

Once the previous planning documents are in place, the ANAO can move ahead with any CJPA identified by a minister, the JCPAA or by the Auditor-General Once approval has been secured, the ANAO should immediately approach the relevant state or territory audit office, to notify them and inquire about possible staff exchange or secondment for the audit. This should allow ample time for the state or territory audit office to prepare for incoming ANAO staff or otherwise loss of their own. Compensation can then be pursued. Once secondment or staff exchange is agreed upon, the ANAO can begin making preparations for the secondees' arrival. Once secondees arrive, the audit team can begin to develop the Audit Work Plan and proceed with their performance audit as normal, but with the additional expertise of the state or territory audit staff.

Following the conclusion and tabling of the performance audit, the ANAO should conduct an evaluation of the CJPA process using the secondment or staff exchange components, to determine whether it was an effective approach. The evaluation should include input from all stakeholders involved in the new CJPA process. 


\section{Conclusion}

The aim of this study was to assess the impacts of the new cross-jurisdictional performance audit powers of the Commonwealth Auditor-General on key stakeholders, including the ANAO, and to explore alternative approaches, such as cooperative audits. First, a review of background information outlining the Australian context was provided, followed by a review of the relevant performance audit literature. Next, a jurisdictional scan was conducted to explore performance audit practices of other national audit agencies, followed by interviews with a range of experts in the field of public audit. Finally, an online survey was administered to solicit international perspectives on CJPAs and cooperative audit approaches.

Findings from the study suggest that impacts of the new CJPA powers are anticipated to be widespread and not without their challenges, but will be concentrated at the state and territory levels, with the bulk of the effects felt by central agencies, auditees and auditors-general. While earlier fears of constitutional challenge on the part of the states appear to have diminished, both the credibility and reputation of the ANAO depend upon the outcomes of these audits. Therefore the ANAO must be diligent in its efforts to mitigate the risks associated with CJPAs through appropriate stakeholder management and by focusing on low sensitivity audits in the early days.

One of the best approaches to mitigating these risks would be to involve the state and territory audit staff through staff exchange or secondments, particularly in the first one to two years of the new CJPA program. This would help address the biggest concerns on the ground that relate to how well and how quickly ANAO staff can familiarise themselves with the state and territory operations, as well as how their new auditees will respond to the presence of federal auditors. It will also satisfy the desire of the state and territory auditors-general to be involved in the CJPA process, while providing overall legitimacy to the federal presence in state and territory jurisdictions. This approach will also be low in cost and does not require additional legislative amendments.

Although the evidence collected here presents a substantial case for the pursuance of more cooperative approaches to performance audit, particularly with respect to the issue of federal financial transfers, it is also clear that these approaches can be time and labor intensive, and still face legislative barriers that restrict information-sharing amongst audit offices. In order to pursue this approach, the ANAO will need to seek additional funding, as will the state and territory auditors-general, and some amendments to information sharing will have to be made at the state and territory level. However, in the medium to 
long term of 5-10 years, this approach holds promise for improved working relationships between audit offices and levels of government more generally, and ultimately improved performance audit outcomes.

\section{References}

Adams, N. 1986, 'Efficiency auditing in the Australian National Audit Office', Australian Journal of Public Administration 45(3), pp. 189-200.

ANAO (Australian National Audit Office) 2008, 'Performance Auditing in the Australian National Audit Office'. Available at: http://www.anao.gov.au/ uploads/documents/Performance_Auditing.pdf.

ANAO 2009, 'Submission to the JCPAA Inquiry into the Auditor-General Act 1997', Submission No. 3. Available at: http://www.aph.gov.au/parliamentary_ business/committees/house_of_representatives_committees?url=jcpaa/ agact/subs.htm.

ANAO 2011, 'About us'. Available at: http://www.anao.gov.au/About-Us.

ANAO 2012a, 'Guidelines for the conduct of performance audits'. Available at: http://www.anao.gov.au/Publications/Corporate-Publications/Guidelinesfor-the-Conduct-of-Performance-Audits.

ANAO 2012b, 'Annual Report 2011-2012'. Availble at: http://www.anao.gov. $\mathrm{au} /$ /media/Files/Annual\%20Reports/Annual\%20Reports/2011_2012_ Annual_Report/ANAO\%20Annual\%20Report\%202011\%202012.pdf.

Aucoin, P. 1990, 'Administrative Reform in Public Management: Paradigms, principles, paradoxes and pendulums', Governance 3(2), pp. 115-137.

Australian Government 2012, 'Final Budget Outcome 2011-12, Part 3: Australia's Federal Relations'. Available at: http:/www.budget.gov.au/2011-12/content/ fbo/html/index.htm.

Barrett, P. 2002, 'Auditing in a Changing Governance Environment', in Papers on Parliament No. 39, Department of the Senate, Canberra.

Barrett, P. 2010, 'Performance auditing: What value?', Journal of Public Money and Management 30(5), pp. 271-278.

Barrett, P. 2011, 'Commentary: Where you sit is what you see: The seven deadly sins of performance auditing: Implications for monitoring public audit institutions', Australian Accounting Review 21(4), pp. 397-405. 
Barzelay, M. 1997, 'Central Audit Institutions and Performance Auditing: A comparative analysis of organizational strategies in the $\mathrm{OECD}^{\prime}$, Governance (Oxford) 10(3), pp. 235-260.

Boadway, R. and Shah, A. (eds) 2007, Intergovernmental Fiscal Transfers: Principles and practice, The World Bank, Washington DC. Available at: http:// documents.worldbank.org/curated/en/2006/11/7242002/intergovernmentalfiscal-transfers-principles-practice.

Bowerman, M., C. Humphrey and D. Owen 2003, 'Struggling for Supremacy: The case of UK public audit institutions', Critical Perspectives on Accounting 14(1), pp. 1-22.

Bundesrechnungshof 1997, 'Audit Rules of the Bundesrechnungshof'. Available at: http://bundesrechnungshof.de.

Bundesrechnungshof 2012, 'Institutional relations'. Available at: http:// bundesrechnungshof.de/international-relations.

CCOLA (Canadian Council of Legislative Auditors) 2007, 'Collaborative audit general guidelines', internal document.

Chelimsky, E. 1985, 'Comparing and Contrasting Auditing and Evaluation: Some notes on their relationship', Evaluation Review 9(4), pp. 483-583.

Clark, I. and H. Swain 2005, 'Distinguishing the Real from the Surreal in Management Reform: Suggestions for beleaguered administrators in the government of Canada', Canadian Public Administration 48(4), pp. 453-476.

English, L. and J. Guthrie 2000, 'Mandate, Independence and Funding: Resolution of a protracted struggle between parliament and the executive over the powers of the Australian Auditor-General', Australian Journal of Public Administration 59(1), pp. 98-114.

English, L. and P. Skaerbaek 2007, 'Performance Auditing and the Modernization of the Public Sector', Financial Accountability and Management 23(3), pp. 239-241.

Fenna, A. 2008, 'Commonwealth Fiscal Power and Australian Federalism', UNSW Law Journal 31(2), pp. 509-529.

Funnell, W. 1996, 'Executive Encroachments on the Independence of the Commonwealth Auditor-General', Australian Journal of Public Administration 55(4), pp. 109-123. 
Funnell, W. 1997, 'The Curse of Sisyphus: Public sector audit independence in an age of economic rationalism', Australian Journal of Public Administration 56(4), pp. 87-105.

Funnell, W. 1998, 'Executive Coercion and State Audit: A processual analysis of the responses of the Australian Audit Office to the dilemmas of efficiency auditing 1978-84', Accounting, Auditing and Accountability Journal 11(4), pp. 436-458.

Funnell, W. 2003, 'Enduring Fundamentals: Constitutional accountability and auditors-general in the reluctant state', Critical Perspectives on Accounting 14(1), pp. 107-132.

Funnell, W. 2011, 'Keeping Secrets?: Or what government performance auditors might not need to know', Critical Perspectives on Accounting 22(7), pp. 714721 .

Funnell, W. and M. Wade 2012, 'Negotiating the Credibility of Performance Auditing', Critical Perspectives on Accounting 23(6), pp. 434-450.

Furubo, J. E. 2011, 'Performance Auditing: Audit or misnomer?', in J. Lonsdale, P. Wilkins and T. Ling (eds), Performance Auditing: Contributing to accountability in democratic government, Edward Elgar, Cheltenham, pp. $22-47$.

Gendron, Y., D. Cooper and B. Townley 2007, 'The Construction of Auditing Expertise in Measuring Government Performance', Accounting, Organizations and Society 32, pp. 101-129.

Gerald, P. 2012, 'Cross-Jurisdictional Performance Audits at the Australian National Audit Office: Impacts and alternatives'. Available at: https://dspace. library.uvic.ca:8443//handle/1828/4383.

Glynn, J. 1985, 'Value for Money Auditing: An international review and comparison', Financial Accountability and Management 1(2), pp. 113-128.

Guthrie, J. 1987, 'Public Sector Audits of Programmes and Management in Australia', Managerial Auditing Journal 2(16), pp. 10-16.

Guthrie, J. 1989, 'The Contested Nature of Performance Auditing in Australia', International Journal of Public Sector Management 2(3), pp. 56-66.

Guthrie, J. and L. Parker 1999, 'A Quarter of a Century of Performance Auditing in the Australian Federal Public Sector: A malleable masque', Abacus (Sydney), 35(3), pp. 302-332. 
Hamburger, P. 1989, 'Efficiency Auditing by the Australian Audit Office: Reform and reaction under three Auditors-General', Accounting, Auditing and Accountability Journal 2(3), pp. 3-21.

Hood, C. 1991, 'A Public Management for all Seasons?', Public Administration 69(1), pp. 3-19.

Hood, C. and G. Peters 2004, 'The Middle Aging of New Public Management: Into the age of paradox?', Journal of Public Administration Research and Theory 14(3), pp. 267-282.

INTOSAI (International Organisation of Supreme Audit Institutions) 1998, 'How SAIs May Cooperate on the Audit of International Environmental Accords'. Available at: http://www.issai.org/media/13180/issai_5140_e.pdf.

INTOSAI 2004, 'Standards and Guidelines for Performance Auditing Based on INTOSAI's Auditing Standards and Practical Experience'. Available at: http://www.intosai.org/issai-executive-summaries/view/article/issai3000-implementation-guidelines-for-performance-auditingstandards-andguidelines-for-perf.html.

INTOSAI 2007, 'Cooperation Between Supreme Audit Institutions: Tips and examples for cooperative audits'. INTOSAI Working Group on Environmental Audit. Available at: www.nik.gov.pl/plik/id,2334,vp,2948.pdf.

INTOSAI 2010, 'Performance Audit Guidelines: Key principles'. Available at: www.issai.org/media/13220/issai_3100_e.pdf.

INTOSAI 2012a, 'Australia: Amendments to the Auditor-General Act 1997', International Journal of Government Auditing 39(4), p. 6.

INTOSAI 2012b, 'Fundamental Principles of Public Sector Auditing'. Available at: $\quad$ www.intosai.org/issai.../issai-100-fundamental-principles-of-publicsector- auditing.html.

INTOSAI 2012c, 'Fundamental Principles of Performance Audits'. Available at: www.issai.org/media/69911/issai-300-english.pdf.

Jacobs, K. 1998, 'Value for Money Auditing in New Zealand: Competing for control in the public sector', The British Accounting Review 30(4), pp. 343360 .

JCPAA (Joint Committee of Public Accounts and Audit) 2010 'Report 419: Inquiry into the Auditor-General Act 1997', Commonwealth of Australia. 
Justesen, L. and P. Skaerbaek 2010, 'Performance Auditing and the Narrating of a New Auditee Identity', Financial Accountability and Management, 26(3), pp. 325-343.

Keen, J. 1999, 'On the Nature of Audit Judgments: The case of value for money studies', Public Administration 77(3), pp. 509-525.

Kells, S. 2011, 'The Seven Deadly Sins of Performance Auditing: Implications for monitoring public audit institutions', Australian Accounting Review 59(21), pp. 383-396.

Leeuw, F. L. 1996, 'Auditing and Evaluation: Bridging a gap, worlds to meet?', New Directions for Evaluation 71, pp. 51-60.

Lonsdale, J. 2000, 'Developments in Value-for-Money Audit Methods: Impacts and implications', International Review of Administrative Sciences 66 (1), pp. 73-89.

Lonsdale, J. 2008, 'Balancing Independence and Responsiveness: A practitioner perspective on the relationships shaping performance audit', Evaluation 14(2), pp. 227-248.

Lonsdale, L., R. Mul and C. Pollitt 1999, ‘The Auditor's Craft: In performance or compliance?', in C. Pollitt (ed.), Performance or Compliance?: Performance audit and public management in five countries, Oxford University Press, Oxford. Available at: http://www.oxfordscholarship.com/view/10.1093/acp rof:oso/9780198296003.001.0001/acprof-9780198296003-chapter-7.

Lonsdale, J., P. Wilkins and T. Ling 2011, Performance Auditing: Contributing to accountability in democratic government, Edward Elgar, Cheltenham.

Mayne, J. 2010, 'Performance Auditing: Cozy, comfortable, and in need of a challenge', Optimum Online 40(3), p. 2.

McPhee, I. 2010, 'Public Hearing 8/02/10', JCPAA Inquiry into the AuditorGeneral Act 1997, p. 8. Available at: http://www.aph.gov.au/Parliamentary_ Business/Committees/House_of_Representatives_Committees?url=jcpaa/ agact/hearings.htm.

McPhee, I. 2011, 'GOTCHA! Or improving administration: The impact of oversight and review agencies', paper delivered at IPAA (ACT) Forum, 23 August 2011. Available at: http://www.anao.gov.au/Publications/Speeches.

McPhee, I. 2012, 'The Evolving Role and Mandate of the Australian National Audit Office Since Federation', Papers on Parliament No. 57, Australian Senate. Available at: http://www.aph.gov.au/About_Parliament/Senate/ Research_and_Education/pops/pop57/c04. 
New Accountabilities, New Challenges

McPhee, I. 2012b, 'Audits of Commonwealth Partner', ANAO presentation at the Australasian Council of Pubic Accounts Committees Mid-Term Meeting, 25 May 2012. Available at: www.anao.gov.au/ /media/Files/Speeches/ACPAC. pdf.

Morin, D. 2001, 'Influence of Value for Money Audit on Public Administrations: Looking beyond appearances', Financial Accountability and Management 17(2), pp. 99-117.

Morin, D. 2008, 'Auditors General's Universe Revisited', Managerial Auditing Journal 23(7), pp. 697-720.

Murray, A. 2011, 'Budgets and Finance: Sunlight and the dark arts', Papers on Parliament No. 56, Australian Senate. Available at: http://www.aph.gov.au/ About_Parliament/Senate/Research_and_Education/pops/pop56.

Nicoll, P. 2005, Audit in a Democracy: The Australian model of public sector audit and its application to emerging markets, Oxford University Press, Oxford.

Office of the Auditor-General of Canada 2007, '2007-08 Estimates - Reports on Plans and Priorities', p. 4. Available at: http://www.tbs-sct.gc.ca/rpp/20072008/oag-bvg/oag-bvg-eng.pdf.

Paun, A. and R. Hazell 2008, 'Centralised Power and Decentralised Politics in the Devolved UK', paper delivered at International Association of Centres for Federal Studies Conference, Barcelona, 20 September 2008.

Podger, A. and J. Wanna 2012, 'Accountability for National Funding Agreements', Thinkpiece Discussion Paper, COAG Reform Council. Available at: https:// www.coagreformcouncil.gov.au/.../Think_piece_Podger_Wanna_2012.pdf.

Pollitt, C. 2006, 'Performance Information for Democracy: The missing link?', Evaluation 12(1), pp. 11-55.

Pollitt, C. and H. Summa 1996, 'Performance Audit and Evaluation: Similar tools, different relationships?', New Directions for Evaluation, 1996(71), pp. 29-50.

Pollitt, C. and H. Summa 1999, 'Performance Audit and Public Management Reform', in C. Pollitt, X. Girre, J. Lonsdale, R. Mul, H. Summa and M. Waerness (eds), Performance of Compliance? Performance audit and public management in five countries, Oxford University Press, Oxford.

Pollitt, C., X. Girre, J. Lonsdale, R. Mul, H. Summa and M. Waerness 1999, Performance or Compliance? Performance audit and public management in five countries, Oxford University Press, Oxford.

Power, M. 1997, The Audit Society, Oxford University Press, Oxford. 
Pugh, C. 1987, 'Efficiency Auditing and the Australian Audit Office', Australian Journal of Public Administration 46(1), p. 55.

Put, V. and R. Turksema 2011, 'Selection of Topics', in J. Lonsdale, P. Wilkins and T. Ling (eds), Performance Auditing: Contributing to accountability in democratic government, Edward Elgar, Cheltenham, pp. 51-74.

Quiggin, J. 2005, 'Untangling the Web of Commonwealth/State/Local Government Funding: What did your GST buy?', presentation at the Housing Industry Association's Home and Building Expo, Brisbane, 26 May 2005.

Riksrevisionen 2011, 'The Act and Instructions Relating to the Office of the Auditor General: With comments'. Available at: https://www.riksrevisjonen. no/en/AboutRR/RoleAndTasks/Documents/ActAndInstructions.pdf.

Robertson, G. 2009, 'Independence of Auditors General: A survey of Australian and New Zealand legislation: A report commissioned by the Victorian Auditor General's Office'. Available at: http://www.acag.org.au/Independence_ ANZ_20090702.pdf.

Shand, D. and P. Anand 1996, 'Performance Auditing in the Public Sector: Approaches and issues in OECD member countries', in Performance Auditing and the Modernization of Government, OECD, Paris, pp. 57-78.

Sharma, N. 2007, 'Interactions and Interrogations: Negotiating and performing value for money reports', Financial Accountability and Management 23(3), pp. 289-311.

Sutherland, S. L. 1986, 'The Politics of Audit: The federal office of the Auditor General in comparative perspective', Canadian Public Administration 29(1), pp. 118-148.

Sutherland, S. L. 2001, 'Biggest Scandal in Canadian history: HRDC audit starts probity war', School of Policy Studies Working Paper No. 23, Queens University.

Sutherland, S. L. 2002, 'The Office of the Auditor General of Canada: Government in exile?', School of Policy Studies Working Paper No. 31, Queen's University.

Talbot, C. and J. Wiggan 2010, 'The Public Value of the National Audit Office', The International Journal of Public Sector Management, 23(1), pp. 54-70.

Taylor, J. 1996, 'What Should be the Role of the Auditor-General in the Context of Managerialist Government and New Public Management?', Australian Journal of Public Administration 55(4), pp. 147-156. 
Twomey, A. and G. Withers 2007, 'Australia's Federal Future: Delivering growth and prosperity: A report for the Council for the Australian Federation', Federalist Paper 1. Available at: http://www.caf.gov.au/documents/ australiasfederalfuture.pdf.

van der Knaap, P. 2011, 'Sense and Complexity: Initiatives in responsive performance audits', Evaluation 17(4), pp. 351-363.

Van Leeuwen, S. 2004, 'Auditing International Environmental Agreements: The role of supreme audit institutions', The Environmentalist 24(2), pp. 93-99.

Van Loocke, E. and V. Put 2011, 'The Impact of Performance Audits: A review of the existing evidence' in J. Lonsdale, P. Wilkins and T. Ling (eds), Performance Auditing: Contributing to accountability in democratic government, Edward Elgar, Cheltenham, pp. 175-208.

Wanna, J., C. Ryan and C. Ng 2001, From Accounting to Accountability: A centenary history of the Australian National Audit Office, Allen \& Unwin, Sydney.

Wanna, J. and A. Podger 2009, 'IPAA Submission to the JCPAA Inquiry into the Auditor-General Act 1997', Submission No. 5. Available at: http://www. aph.gov.au/parliamentary_business/committees/house_of_representatives_ committees?url=jcpaa/agact/subs.htm.

WGEA (Working Group on Environmental Auditing) 2012, 'Audits by Country: Austria'. Available at: www.environmental-auditing.org/tabid/126/ CountryId/346/Default.aspx.

Wilkins, P. 1995, 'Performing Auditors: Assessing and reporting the performance of national audit offices: A three country comparison', Australian Journal of Public Administration 54(4), pp. 421-430.

\section{Appendix 1: List of interview participants}

Biography information for interview participants has been gathered from the various audit office websites as well as through general internet searches.

- Ian McPhee (ANAO) — Ian McPhee was appointed as Auditor-General for Australia in March 2005. His previous position was as Deputy Secretary, Financial Management Group, Department of Finance and Administration, where his responsibilities included managing and providing policy advice to the Finance Minister on the budget and financial management framework; budget and financial reporting, and analysis for whole of government 
purposes; public sector superannuation; and the Office of Evaluation of Audit. From 1998 to January 2003, Ian was Deputy Auditor-General at the ANAO, where he was responsible to the Auditor-General for the delivery of the performance and assurance audit programs.

- Russell Coleman (ANAO) - Russell Coleman is a senior staff member at the ANAO and has worked for the office in various capacities for close to 30 years.

- Andrew Greaves (QLD) - Andrew Greaves became the Auditor-General of Queensland in December 2011. Prior to this appointment, Andrew had been an Assistant Auditor-General at the Victorian Auditor-General's Office since 2006 and headed both the Financial Audit Group and the Performance Audit Group. Andrew has over 27 years experience in public sector external and internal audit, at the Commonwealth, state and local government levels.

- Colin Murphy (WA) - Colin Murphy was appointed Auditor-General for Western Australia in June 2007. Colin has extensive experience in finance and administration in State and Commonwealth government roles. He has held senior positions within the state government in the Departments of Justice, Treasury and Finance, Land Administration, and the Building Management Authority. He has also worked for the Commonwealth Department of Finance in Perth and Washington DC, and as Business Manager for Murdoch University. Colin is a member of the Australian Auditing and Assurance Standards Board. He holds a Bachelor of Commerce degree from the University of Western Australia. He is a Fellow, former board member and past State President of CPA Australia and a Fellow of Chartered Secretaries Australia and the Institute of Chartered Accountants in Australia.

- Des Pearson (VIC) — Des Pearson was appointed Auditor-General of Victoria in October 2006. He was previously Auditor-General of Western Australia from 1991 to 2006. He has been an involved member of CPA Australia, the Institute of Public Administration, and the Australian Institute of Management.

- Mike Blake (TAS) — Mike Blake was appointed Tasmanian Auditor-General in May 2004. Prior to accepting the position, he was Auditor-General for the Northern Territory and had previous worked as the Deputy AuditorGeneral of Western Australia. Mike has been an active member of the Public Sector Accounting Standards Board from 1994 to 1999, a member of the Urgent Issues Group representing Auditors-General from 2003 to 2005 and was appointed to the Auditing and Assurance Standards Board on 1 January 2006. Mike is a Fellow of ICA Australia and of CPA Australia.

- Frank McGuiness (NT) — Frank McGuiness was appointed as the AuditorGeneral of the Northern Territory in September 2004. He previously held senior positions in the Northern Territory and South Australian Treasuries. 
Originally from South Australia, Frank completed an undergraduate degree in economics and a Master of Financial Management degree.

- Megan Young (ACT) - Megan Young is a Senior Audit Manager at the ACT Auditor General's Office.

- Rob Oakeshott, MP - Rob Oakeshott is an independent member of Parliament for Lyne, an electorate situated on the mid-north coast of New South Wales. Since joining federal Parliament in September 2008, Rob has invested heavily in committee work, including his current chairmanship of the Joint Committee of Public Accounts and Audit and the Standing Committee on the National Broadband Network. Rob played a figurative role in the amendments to the Commonwealth Auditor-General Act both as Chair of the JCPAA and after introducing a private member's bill supporting the amendments in 2011.

- Russell Chafer, former Secretary of the JCPAA - Russell Chafer was the Secretary for the JCPAA during the time of the Inquiry into the AuditorGeneral Act 1997, but has since moved to the Clerk's Office at the House of Representatives.

- Pat Barrett, former Commonwealth Auditor-General - Pat Barrett served a 10-year term as Auditor-General for Australia until 2005. He is now a Senior Fellow at ANU Australian National Centre for Audit and Assurance Research and has expertise in numerous areas including public sector management, information technology, and financial, auditing and budgeting issues. He is a member of the Board of Governors of the International Federation of Accountants, the peak body of accountants in the world responsible for the International Auditing and Assurance Standards Board and the International Public Sector Accounting Standards Board. Mr. Barrett is also a prolific writer on the subject of auditing, accounting, and public management, and many of his papers have been published in either books or journals.

- Glenn Poole, former Auditor General for Queensland - Glenn Poole served as Queensland's Auditor-General from 2004 to 2011. Prior to that he was a senior executive in the Queensland Treasury Department for over 15 years. Glenn is now Executive in Residence at the Australian Centre for Philanthropy and Nonprofit Studies at Queensland University of Technology in Brisbane. 
12. Cross-Jurisdictional Performance Audits

\section{Appendix 2: Comparison of legislative powers of Australian auditors-general}

\begin{tabular}{|l|l|l|l|l|l|l|l|l|l|}
\hline & CW & ACT & NT & NSW & QLD & SA & TAS & VIC & WA \\
\hline $\begin{array}{l}\text { Explicit right } \\
\text { to conduct } \\
\text { joint audits }\end{array}$ & No & No & No & No & $\begin{array}{l}\text { Yes } \\
\text { (2011) }\end{array}$ & No & No & No & No \\
\hline $\begin{array}{l}\text { Right to share } \\
\text { information }\end{array}$ & No & No & $\begin{array}{l}\text { Not } \\
\text { explicit } \\
\text { but } \\
\text { flexible* }\end{array}$ & No & $\begin{array}{l}\text { Yes } \\
\text { (2011) }\end{array}$ & No & $\begin{array}{l}\text { Yes } \\
\text { (2011) }\end{array}$ & No & $\begin{array}{l}\text { Yes } \\
\text { (2006) }\end{array}$ \\
\hline $\begin{array}{l}\text { Right to } \\
\text { follow-the- } \\
\text { money into } \\
\text { third parties } \\
\text { (NGOs, private } \\
\text { contractors) }\end{array}$ & $\begin{array}{l}\text { Yes } \\
(2011)\end{array}$ & $\begin{array}{l}\text { Pursuing } \\
\text { (2012) }\end{array}$ & $\begin{array}{l}\text { Yes } \\
(2011)\end{array}$ & No & $\begin{array}{l}\text { Yes } \\
\text { (2011) }\end{array}$ & No & $\begin{array}{l}\text { Yes, } \\
\text { (2008) }\end{array}$ & No & $\begin{array}{l}\text { Yes } \\
\text { (2006) }\end{array}$ \\
\hline $\begin{array}{l}\text { Power to } \\
\text { follow- } \\
\text { the-money } \\
\text { into local } \\
\text { government }\end{array}$ & Yes & Yes & Yes & No & Yes & No & Yes & Yes & No \\
\hline
\end{tabular}

* This possibility was outlined in an interview with the Auditor-General for the Northern Territory 
This text taken from New Accountabilities, New Challenges, edited by John Wanna, Evert A. Lindquist and Penelope Marshall, published 2015 by ANU Press, The Australian National University, Canberra, Australia. 